\title{
MODESTO BARGALLÓ EN ESPAÑA (1894-1939): UNA BIOGRAFÍA ENTRE LA HISTORIA DE LA EDUCACIÓN Y LA HISTORIA DE LA CIENCIA ${ }^{\alpha}$
}

\author{
Modesto Bargalló in Spain (1894-1939): A biography between the \\ history of education and the history of science
}

\section{Luis Moreno Martínez ${ }^{\circledR}$}

Fecha de recepción: 12/05/2020 • Fecha de aceptación: 16/07/2020

Resumen. El presente trabajo ahonda en la trayectoria profesional de Modesto Bargalló Ardévol (1894-1981) en España. Se trata de uno de los principales actores en la renovación pedagógica de la enseñanza de las ciencias en España del primer tercio del siglo XX. A partir de la revisión de los estudios biográficos publicados sobre este docente normalista y del análisis de su prolífica producción impresa y de otras fuentes documentales, se abordan diferentes cuestiones que se revelaban pendientes en el estudio de su obra en España. El relato biográfico confeccionado permite así reflexionar sobre el empleo de las biografías del profesorado como herramientas metodológicas para explorar la historia de la educación científica y sobre el papel de esta última como un espacio de investigación compartido entre historiadores de la educación e historiadores de la ciencia.

Palabras clave: Modesto Bargalló; biografías; enseñanza de las ciencias.

Abstract. This paper deals with the professional career of Modesto Bargallo Ardévol (1894-1981) in Spain, who has been singled out as a one of the outstanding renovators of Spanish science teaching in the first third of the 20th century. After undertaking a review of the biographical studies of this train-

\footnotetext{
${ }^{\alpha}$ Investigación financiada por una Beca para Tesis Doctorales en Historia de la Ciencia de la Fundación Juanelo Turriano y ampliada en el marco de una Beca de Excelencia Postdoctoral del Gobierno de México.

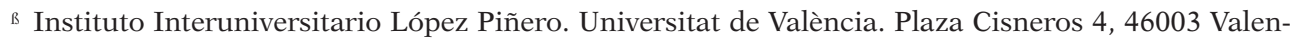
cia. España. luis.moreno-martinez@uv.es https://orcid.org/0000-0002-4540-5752
} 
ing-school professor and an analysis of his wide range of publications and other historical sources, the paper focuses on several neglected questions regarding his work in Spain. I will argue that Modesto Bargallós biography can contribute to a reflection on the use of teacher biographies for exploring the history of science education and its role as a field of scholarship shared by historians of education and science historians.

Keywords: Modesto Bargalló; biographies; science teaching.

\section{INTRODUCCIÓN}

Escribir una vida es entablar un diálogo pautado entre biógrafo, biografiado y público lector. Las pautas que guían dicho diálogo son múltiples, motivo por el cual existe una amplia y dilatada reflexión sobre el ejercicio de escritura biográfica, renovada en los últimos años. ${ }^{1}$ La aproximación biográfica como herramienta metodológica en investigación histórica exige un ineludible ejercicio de análisis sobre, al menos, cuatro cuestiones: la tensión tiempo-temática o la cuestión de la secuenciación, la tensión individuo-contexto o la cuestión de la especificidad, la tensión continuidad-exhaustividad o la cuestión de la aporía y la tensión biógrafo-demiurgo o la cuestión de la proximidad. ${ }^{2}$ Todas estas cuestiones han sido consideradas en la confección del relato biográfico sobre Modesto Bargalló Ardévol en España que se ofrece en el presente trabajo.

La mirada analítica dirigida a la biografía de este actor destacado de la enseñanza de las ciencias del primer tercio del siglo XX se ha secuenciado atendiendo tanto a un enfoque cronológico (plutarquiano) como temático (suetoniano). ${ }^{3}$ Así, si bien se atenderá a sus vivencias (bios) y su quehacer profesional (ergon) en España desde su nacimiento en 1894 hasta su exilio en México en 1939, dicho recorrido biográfico se focalizará en una serie de temáticas específicas como su papel como discente, docente, traductor, editor y autor. Asimismo, la especificidad del relato

\footnotetext{
${ }^{1}$ Isabel Burdiel y Roy Foster, La historia biográfica de Europa. Nuevas perspectivas (Zaragoza: Fundación Fernando El Católico, 2015).

2 François Dosse, La apuesta biográfica. Escribir una vida (Valencia: Publicaciones de la Universitat de València, 2007).

3 Thomas Söderqvist, «"No Genre of History Fell Under More Odium than that of Biography": The Delicate Relations Between Scientific Biography and the Historiography of Science», en The History and Poetics of Scientific Biography, ed. Thomas Söderqvist (Nueva York: Routledge, 2007), 242-262.
} 
biográfico es concebida como un elemento de profundo interés a fin de construir una historia de la educación científica que huya de «individualizar aquellas personalidades que la historia ha reunido», ${ }^{4}$ que revele «la enorme gama de grises que esconde cualquier individuo» y que permita huir de una interpretación del pasado mediante "procesos reduccionistas de catalogación». ${ }^{5}$ Todo ello considerando que el ejercicio de escritura biográfica es intrínsecamente una aporía, en el que siempre quedan vacíos debidos tanto a los objetivos que persiguen los biógrafos (cambiantes en el tiempo) como a la ausencia de fuentes históricas ligadas al biografiado (perdidas en el tiempo). Finalmente, el diálogo entre biógrafo y biografiado se ha realizado desde la gran empatía 6 necesaria para poder profundizar en los anhelos, los fracasos o las contradicciones del sujeto histórico; y desde la justa distancia, ${ }^{7}$ que previene de la hagiografía.

La confección de dicha mirada analítica ha sido posible gracias a la labor de recuperación del personaje realizada por diferentes investigadores que desde antes incluso del fallecimiento de Bargalló en México D.F. (hoy, Ciudad de México) en 1981 ya acometieron la escritura de su biografía. Estos trabajos han situado a la biografía de Bargalló entre la historia de la educación y la historia de la ciencia, historiografías que no siempre se han desarrollado con claros puntos de encuentro y diálogo. ${ }^{8}$ Dichos relatos biográficos han sido producidos con fines diferenciados y atendiendo a cuestiones diversas. Por ello, antes de ofrecer una mirada analítica a la biografía de Bargalló atendiendo a diferentes facetas de su vida y su obra en España, se ha hecho necesario un análisis de los principales estudios biográficos publicados sobre Bargalló a fin de identificar dichos fines y localizar las cuestiones que se revelaban pendientes. Dicho análisis se recoge a continuación.

\footnotetext{
${ }^{4}$ Dosse, La apuesta biográfica, 57.

5 María del Mar del Pozo Andrés, Justa Freire o la pasión de educar: Biografía de una maestra atrapada en la historia de España (1896-1965) (Barcelona: Octaedro, 2013), 14.

6 Pozo Andrés, Justa Freire o la pasión de educar, 14.

7 Dosse, La apuesta biográfica, 14.

8 José Ramón Bertomeu Sánchez, «Beyond Borders in the History of Science Education», en Relocating the History of Science: Essays in Honor of Kostas Gavroglu, ed. Theodore Arabatzis, Jürgen Renn y Anna Simoes (Dordrecht: Springer, 2016), 159-173.
} 


\section{MODESTO BARGALLÓ COMO OBJETO DE ESTUDIO}

Desde su fallecimiento en Ciudad de México el 1 de julio de 1981, varios estudios han abordado la biografía de Modesto Bargalló. El interés por el exilio científico, la recuperación del colectivo normalista en el ámbito de la historiografía educativa, la reivindicación de las contribuciones bargallianas a las ciencias naturales (como la geología o la paleontología) o la historia local de Guadalajara han sido algunos temas que han propiciado estudios sobre su figura, con diferentes niveles de detalle, escala y precisión. El propio Bargalló fue lector de una de las primeras biografías publicadas sobre él, la cual fue incluida como prólogo a su obra Trabajos, artículos y apuntes (1940-1972) sobre química, enseñanza y metalurgia mexicana y de Hispanoamérica colonial. ${ }^{9}$ Esta biografía fue elaborada por Héctor Mayagoitia (entonces, subsecretario de Educación Media, Técnica y Superior de la Secretaría de Educación de México), Fidel Villareal (profesor del Instituto Tecnológico y de Estudios Superiores de Monterrey) y José Ignacio Bolívar (profesor de la Universidad Autónoma de México). ${ }^{10}$ Aunque no se trata de un texto autobiográfico en sentido estricto, al haber sido incluido en una obra autoeditada por el propio Bargalló, cabe esperar que él mismo lo leyese e incluso lo revisase, de modo que hoy dicho apunte biográfico nos informa en cierto modo de la forma en que el propio Bargalló quería ser presentado y recordado. Especial mención merecen las líneas con las que estos autores finalizaban la biografía de Bargalló:

El árbol se conoce por sus frutos. Todo juicio sobre la calidad humana, intelectual y docente del maestro Bargalló, sería redundante si se tratara de adjetivar lo sustantivo de una vida plena y cabal. Y el reconocimiento de todos los que somos deudores de su esfuerzo personal, habrá de prolongarse en las generaciones que sigan aprovechando estos frutos. ${ }^{11}$

\footnotetext{
9 Modesto Bargalló, Trabajos, artículos y apuntes (1940-1972) sobre química, enseñanza y metalurgia mexicana y de Hispanoamérica colonial (México: Edición del autor, 1973).

10 Héctor Mayagoitia, Fidel Villareal y Isabel Bolívar, «Modesto Bargalló: Su vida docente y su obra», en Trabajos, artículos y apuntes (1940-1972) sobre química, enseñanza y metalurgia mexicana y de Hispanoamérica colonial, ed. Modesto Bargalló (México: Edición del autor, 1973): IX-XII.

11 Mayagoitia, Villareal y Bolívar, «Modesto Bargalló: su vida y su obra», XII.
} 
Desde entonces, los diversos trabajos publicados sobre Bargalló han tratado de recuperar dichos frutos. Un año después de su fallecimiento, una nota biográfica sobre Bargalló aparecía en el Índice biográfico del exilio español en México, publicado como apéndice a la obra El exilio español en México (1939-1982) que editó Salvador Reyes Nevares. ${ }^{12} \mathrm{La}$ presencia de Bargalló en dicho índice muestra la notoriedad lograda por Bargalló en México, donde transcurrió prácticamente la mitad de su vida y donde desarrolló una prolífica y reconocida carrera profesional. En este apunte biográfico se presentaba a Bargalló como químico, educador e historiador de la ciencia, se destacaba su trabajo en España en el ámbito de la enseñanza de las ciencias y se afirmaba que, tras llegar a México en 1939, continuó su significativa actividad como historiador de la ciencia; lo que deja a la interpretación del lector la dedicación de Bargalló a la historia de la ciencia en sus años en España. Esta obra también incluía información biográfica en el capítulo dedicado a las contribuciones de los exiliados en las áreas de matemáticas, física y química. ${ }^{13} \mathrm{En}$ dicho capítulo se indicaba que Bargalló «se graduó de maestro elemental y superior, y de licenciado y doctor en ciencias» en España. ${ }^{14}$

Estas referencias a la formación de Bargalló perdurarán en trabajos más recientes sobre el exilio científico en México. Así, el doctor Bargalló será presentado como un "excelente químico» y un "consumado historiador de esta ciencia» en Los maestros del exilio español en el Instituto Politécnico Nacional, institución donde desarrolló la práctica totalidad de su quehacer profesional en México. ${ }^{15}$ Sin embargo, en la biografía que él mismo incluyó en su trabajo recopilatorio de 1973, Bargalló no era presentado como doctor, sino que se mencionaba que «cursó los estudios de Licenciado en Ciencias Naturales en la Universidad Central de Madrid», donde «hizo los estudios de su Doctorado». ${ }^{16}$ Del mismo modo, será frecuente encontrar referencias a Bargalló como químico en otras

\footnotetext{
12 Salvador Reyes Nevares, El exilio español en México, 1939-1982 (México: Fondo de Cultura Económica, 1982).

13 José Cueli, «Matemáticas, físicas y química», en El exilio español en México, 1939-1982, ed. Salvador Reyes Nevares (México: Fondo de Cultura Económica, 1982), 531-543.

${ }^{14}$ Cueli, «Matemáticas, físicas y química», 541.

15 Silvia Mónica García Bernal, Los maestros del exilio español en el Instituto Politécnico Nacional (Ciudad de México: Ediciones IPN, 2014), 140.

16 Bargalló, Trabajos, artículos y apuntes (1940-1972), IX.
} 
publicaciones sobre el exilio científico republicano. Así aparecerá mencionado, por ejemplo, en Ciencia española en el exilio (1939-1988), obra publicada por el también exiliado Francisco Giral. ${ }^{17}$ En otros trabajos, Bargalló también será presentado como un químico español que se transformó en mexicano. ${ }^{18}$ Como se mostrará, su papel como químico y la ambigüedad sobre su doctorado pueden ser entendidas como consecuencia de la traslación de su ergon en México a su bios en España.

Con independencia de su formación universitaria, Bargalló apenas es mencionado en las narrativas históricas sobre la química del siglo XX en España, pese a contar con sobrados méritos para ello. En esta línea, cabe destacar que se trata del primer español que obtuvo el premio Dexter que otorgaba la History of Chemistry Division de la American Chemical Society, una de las principales sociedades científicas internacionales. Bargalló obtuvo dicho reconocimiento en 1977 por sus múltiples contribuciones a la historia de la química, la minería y la metalurgia. Fruto de ello es posible encontrar un breve apunte biográfico sobre Bargalló en un artículo que Aaron J. Ihde publicó en el Bulletin for the History of Chemistry de dicha sociedad. ${ }^{19}$ Más recientemente se ha aludido a Bargalló en un artículo sobre la historia de la enseñanza de la química en España publicado en Anales de Química, la revista de la Real Sociedad Española de Química; ${ }^{20}$ o en el reciente libro de Agustí Nieto-Galan sobre la química en el franquismo. ${ }^{21}$

No obstante, uno de los ámbitos en el que se ha realizado un mayor esfuerzo por recuperar en detalle la obra bargalliana lo encontramos en la historia de la educación. Bargalló realizó prácticamente la totalidad

\footnotetext{
${ }_{17}$ Francisco Giral, Ciencia española en el exilio (1939-1989). El exilio de los científicos españoles (Barcelona: Antrophos, 1994).

18 Andoni Garritz y Ricardo Valdez, «Modesto Bargalló Ardévol. Un químico español que se transformó en mexicano», Educación Química 19, 1 (2008): 1-8. También se incluye información biográfica sobre Bargalló en: Andoni Garriz et al., «Exiled Chemists of the Spanish Civil War's Footprint in Mexico», History Research 3, 1(2013): 16-25.

19 Aaron J. Ihde, «The history of the Dexter Award. Part IV: The Third Decade», Bulletin for the History of Chemistry, 4(1989): 23-26.

${ }_{20}$ Manuela Martín Sánchez, Gabriel Pinto Cañón y María Teresa Martín Sánchez, «Una aproximación a la historia de la enseñanza de la química universitaria en España», Anales de Química 113, 2(2017): 100-112.

${ }^{21}$ Agustí Nieto-Galan, The Politics of Chemistry. Science and Power in Twentieth-Century Spain (Cambridge: Cambridge University Press, 2019).
} 
de su quehacer docente en la Escuela Normal de Maestros de Guadalajara, antecesora de la actual Facultad de Educación de la Universidad de Alcalá de Henares. En dicha institución, varios historiadores de la educación llevaron a cabo una labor pionera en el estudio detallado del quehacer profesional de Bargalló como docente normalista en España hasta la Guerra Civil. Esta labor dio lugar a la obra Guadalajara en la historia del magisterio español. 1839/1939. Cien años de formación del profesorado, publicada tan solo cinco años después de la muerte de Bargalló por María del Mar del Pozo, Manuel Segura y Alejandro Diez y dedicada, in memoriam, al propio Bargalló. ${ }^{22}$ No sorprende pues que de entre el elenco de profesores cuyas biografías son recuperadas en esta obra, la de Bargalló fuese la más extensa y detallada.

Con anterioridad a esta publicación de 1986, los autores mencionados presentaron un trabajo sobre Bargalló en el III Congreso de la Sociedad Española de Historia de las Ciencias celebrado en San Sebastián en 1984. ${ }^{23}$ Los autores destacaron el papel de instituciones como la Escuela de Estudios Superiores del Magisterio y el Museo Pedagógico Nacional, o docentes como Luis de Zulueta, Edmundo Lozano y Manuel Bartolomé Cossío en su formación. También se apuntaba el interés de Bargalló en la obra de Santiago Ramón y Cajal o la importancia concedida por Bargalló a la historia de la ciencia. ${ }^{24}$ La mirada biográfica ofrecida en estas líneas y otras investigaciones recientes sobre el proyecto pedagógico bargalliano han permitido corroborar y ampliar dichas conclusiones.

La obra de Modesto Bargalló también fue objeto de una de las ponencias del I Congreso Internacional sobre Investigación en Didáctica de las Ciencias y de las Matemáticas organizado por el equipo editorial de la revista Enseñanza de las Ciencias y celebrado en Barcelona en 1985, también a cargo de Pozo Andrés, Segura y Diez. El tema de su comunicación

\footnotetext{
22 María del Mar del Pozo Andrés, Manuel Segura Redondo y Alejandro Díez Torre, Guadalajara en la historia del magisterio español (1839-1939), cien años de formación del profesorado (Guadalajara: Publicaciones de la Universidad de Alcalá de Henares, 1986).

${ }^{23}$ Manuel Segura Redondo, Alejandro Díez Torre y María del Mar del Pozo Andrés, «Aportaciones a la didáctica de las ciencias naturales de Modesto Bargalló durante su etapa de docencia en la Escuela Normal de Guadalajara (1914-1936)», en Actas del III Congreso de la Sociedad Española de Historia de las Ciencias (San Sebastián: Sociedad Española de Historia de las Ciencias y de las Técnicas, 1984): 215-242.

${ }_{24}$ Segura Redondo, Díez Torre y Pozo Andrés, «Aportaciones a la didáctica de las ciencias», 225.
} 
fue en esta ocasión la obra didáctica de Bargalló durante la Segunda República. ${ }^{25}$ Como revela la publicación derivada de dicha ponencia, los autores asumieron la maduración metodológica y la especialización científica de Bargalló como las bases de sus propuestas renovadoras, destacando su "visión moderna y anticipada de la ciencia como un sistema que no se da, sino que se reconstruye». ${ }^{26}$ Se trata de una cuestión en clara imbricación con la defensa de la historia de la ciencia como aspecto central para la didáctica de las ciencias, tal y como defendió Bargalló. Todos estos trabajos contribuyeron a proporcionar una amplia pléyade de información biográfica y rasgos definitorios del proyecto pedagógico bargalliano. Investigaciones recientes han ahondado en estas cuestiones. Asimismo, como se mostrará, la actitud de Bargalló ante ciertos cambios derivados de la implantación del plan de 1931 muestran las dificultades de la conciliación entre quehacer docente y actividad editorial.

Pese a las múltiples contribuciones de Bargalló a la didáctica de las ciencias, la forja de discursos genealógicos de esta como didáctica específica ha dejado fuera a personajes como Bargalló y otros educadores anteriores a su consolidación disciplinar. Este fue precisamente el punto de partida de la obra Renovación Pedagógica y Enseñanza de las Ciencias, publicada por José Mariano Bernal Martínez en 2001.27 En la misma se abordaban las propuestas y experiencias didácticas renovadoras emprendidas por diferentes educadores en España entre 1882 y 1936. El autor pretendía así reivindicar la importancia de la aproximación histórica a la hora de abordar problemas actuales de la didáctica de las ciencias experimentales, donde la labor de docentes como Bargalló habría sido desatendida, cuando no olvidada. Bernal Martínez incluyó entre estos educadores a Modesto Bargalló, al que presentaba como «un nuevo modelo de profesor de ciencias» para las escuelas normales, que fue «capaz de elevar el nivel científico del magisterio español».28 $\mathrm{Al}$ igual que

\footnotetext{
${ }_{25}$ María del Mar del Pozo Andrés, Alejandro Díez Torre y Manuel Segura Redondo, «El modelo de enseñanza metodológica de las ciencias en Modesto Bargalló en el ámbito del plan profesional del Magisterio (1931-1936)», Enseñanza de las Ciencias 3, no. Extra. 1 (1985): 24.

${ }_{26}$ Pozo Andrés, Díez Torre y Segura Redondo, «El modelo de enseñanza metodológica», 24.

27 José Mariano Bernal Martínez, Renovación pedagógica y enseñanza de las ciencias. Medio siglo de propuestas pedagógicas y experiencias escolares (1882-1936) (Madrid: Biblioteca Nueva, 2001).

${ }_{28}$ Bernal Martínez, Renovación pedagógica y enseñanza de las ciencias, 146.
} 
en trabajos anteriores, Bernal Martínez destacó la importancia de la historia de la ciencia en la obra pedagógica de Modesto Bargalló.

Recuperar el nombre y la labor de Bargalló en la didáctica de las ciencias fue un objetivo compartido con los organizadores del simposio Innovación en la Enseñanza de las Ciencias hasta 1936 celebrado en la Universidad de Alcalá de Henares en 2007 con motivo del Año de la Ciencia, el cual acogió la Exposición-Homenaje al profesor Modesto Bargalló. En el catálogo de la misma aparece información biográfica de interés, entre ella el testimonio de uno de sus alumnos en la Escuela Normal de Maestros de Guadalajara, Avelino Antón. La información recogida por el coordinador, José María Sánchez, y los comisarios de la exposición, Alberto Gomis y Manuel Segura, fue ampliada en el artículo que los mismos publicaron en 2011 en la revista de la Sociedad Española de Historia de las Ciencias y las Técnicas, Llull. ${ }^{29}$ Dicho trabajo recuperaba buena parte de la información biográfica entonces disponible sobre Bargalló, con una lista de algunos de sus trabajos en España y México y una descripción sintética de sus principales líneas de actuación e ideas pedagógicas. También se puede enmarcar en esta línea el trabajo presentado por Daniel Carral en el XVIII Coloquio de Historia de la Educación organizado por la Sociedad Española de Historia de la Educación y celebrado en Vic en 2015, quien abordó las propuestas de Bargalló para el estudio de la naturaleza. ${ }^{30}$

En los últimos años han sido objeto de recuperación y estudio las contribuciones de Bargalló al conocimiento de la geología de la Alcarria y su labor pionera en el descubrimiento de varios yacimientos paleontológicos en la provincia de Guadalajara. ${ }^{31}$ En esta línea, cabe mencionar

\footnotetext{
${ }_{29}$ Manuel Segura, Alberto Gomis y José María Sánchez Jiménez, «Modesto Bargalló Ardévol (18941981), maestro de maestros e historiador de la ciencia», Llull 34 (2011), 74: 419-442.

30 Diego Carral, «Modesto Bargalló: El arte de educar en la naturaleza», en Actas del XVIII Coloquio de Historia de la Educación, 2 (2015): 481-486.

31 Me refiero principalmente a: Julia Audije Gil, Fernando Barroso Barcenilla y Manuel Segura Redondo, "Recuperación de la Colección Histórica Bargalló de la Universidad de Alcalá», Geo-Temas 16, 2 (2016): 235-238; Julia Audije Gil, Fernando Barroso Barcenilla y Manuel Segura Redondo, «The Bargalló Teaching Methodology Research and Geological Heritage», Geoheritage 10, 3 (2018): 343-352; Manuel Segura y Alberto Gomis, «Las comunicaciones paleontológicas de Modesto Bargalló presentadas en la Real Sociedad Española de Historia Natural», Boletín de la Real Sociedad Española de Historia Natural, 106 (2012): 85-98; Jaime Truyols y Manuel Segura, Contribuciones de Modesto Bargalló al conocimiento de la geología de la Alcarria, Geogaceta, 20 (1996): 1429-1432.
} 
la labor de recuperación y catalogación de las colecciones de rocas, minerales y fósiles creada por Bargalló en la Escuela Normal de Maestros de Guadalajara. Estos materiales fueron el eje central de la exposición Historia de la Colección Bargalló de rocas y fósiles comisionada por Julia Audije-Gil y Manuel Segura, la cual fue acogida por la Universidad de Alcalá de Henares en 2017 con motivo del 175 aniversario de la Facultad de Educación. ${ }^{32}$

A los trabajos presentados anteriormente, cabe añadir las referencias a Bargalló en otros ámbitos, como el de la historia de la prensa pedagógica, dado su papel en la dirección de la Revista de Escuelas Normales. Esta visibilidad en el ámbito normalista lograda por su faceta como editor hace posible encontrar referencias a Bargalló en estudios históricos sobre otras cuestiones, como la sociogénesis de la didáctica de las ciencias sociales. ${ }^{33}$ Sin embargo, otro de sus proyectos editoriales, el boletín Faraday, si bien ha sido señalado como «la primera revista española dedicada a la didáctica e historia de la ciencia» ${ }^{34}$ no ha sido recuperado y analizado hasta fechas recientes. ${ }^{35}$

En el ámbito político, es posible encontrar una entrada dedicada a Modesto Bargalló en el diccionario biográfico del socialismo español de la Fundación Pablo Iglesias. ${ }^{36}$ Años después, ya en el exilio en México, confesará que aunque en España simpatizó con el Partido Socialista, no llegó a afiliarse. ${ }^{37}$ Finalmente, cabe destacar la memoria alcarreña como

\footnotetext{
32 Julia Aduije Gil, Alberto Gomis y Manuel Segura, Una mirada a la colección Bargalló (Guadalajara: Universidad de Alcalá de Henares, 2017).

33 Juan Mainer Baqué, La forja de un campo profesional. Pedagogía y didáctica de las ciencias sociales en España (1900-1970) (Madrid: CSIC, 2009).

${ }^{34}$ Antonio Checa Godoy, Historia de la prensa pedagógica en España (Sevilla: Publicaciones de la Universidad de Sevilla, 2002), 243.

${ }^{35}$ Luis Moreno Martínez, «Ciencia en las aulas: Prácticas pedagógicas, cultura material e historia de la ciencia en la obra de Modesto Bargalló en España (1894-1939)» (Tesis doctoral, Universitat de València, 2020).

36 Diccionario Biográfico del Socialismo Español, «Modesto Bargalló Ardévol», Fundación Pablo Iglesias. http://www.fpabloiglesias.es/archivo-y-biblioteca/diccionario-biografico/biografias/2257_bargallo-ardevol-modesto (consultado el 8-5-2020).

37 En la entrevista que Modesto Bargalló Ardévol concedió el 23 de julio de 1979 en su domicilio en Coyoacán (Ciudad de México) a la historiadora Matilde Mantecón, afirmó que consideraba al Partido Socialista como «el que poseía gente de más valor» y «de una limpieza casi extrema». No obstante, apuntó que nunca se afilió al partido, ni a ningún otro. Asimismo, confesó que la primera vez que pudo votar en España lo hizo al Partido Socialista. Véase: Matilde Mantecón, «Entrevista a Modesto
} 
otro ámbito en el que será posible encontrar relatos biográficos sobre Bargalló, como su entrada en Enwada, ${ }^{38}$ proyecto de difusión cultural impulsado por el Ayuntamiento de Guadalajara. En este sentido también apunta el reciente homenaje celebrado a la familia Bargalló en el instituto histórico Domínguez Ortíz de Azuqueca de Henares (Guadalajara) en 2019 en el que participó su nieta Sara Cortés Bargalló. ${ }^{39}$

Si se analizan los trabajos anteriores desde el prisma de los estudios sobre confección de biografías científicas, ${ }^{40}$ es posible colegir que la finalidad de los estudios biográficos sobre Bargalló han oscilado entre el panegírico, la conmemoración institucional y la contextualización de su trayectoria en el contexto científico y pedagógico en el que se desarrolló. Asimismo, se trata en su mayoría de biografías centradas en su obra pedagógica y científica, lo que permitió identificar otras facetas poco exploradas como sus años como discente y su quehacer como autor, editor y traductor. Se trata de facetas que permiten comprender desde una perspectiva holística su quehacer profesional como docente, a la par que añaden capítulos poco conocidos de su biografía como la relevancia de sus orígenes sociales, sus vínculos con el sector editorial, sus proyectos fallidos, las estrategias que adoptó para promover sus textos o las obras que finalmente nunca vieron la luz. Todas estas cuestiones serán abordadas en la biografía ofrecida en el presente trabajo.

Finalmente, cabe destacar la profunda imbricación entre la biografía de Bargalló en España y en México. Si bien la segunda será objeto de estudio en futuros trabajos, la primera aquí ofrecida se revela fundamental a fin de explorar continuidades y rupturas, evitando concebir al Bargalló mexicano como una mera traslación de su ergon en España a un

Bargalló», 23 de julio de 1979, p. 20, Fondo PHO/10/38, Archivo de la Palabra, Instituto Nacional de Antropología e Historia (INAH-México). El audio completo de la entrevista se puede escuchar en: https://mediateca.inah.gob.mx/repositorio/islandora/object/entrevista:832 (consultado el 14-7-2020).

38 Enwada-Enciclopedia de Guadalajara, «Modesto Bargalló Ardévol», Enwada-Enciclopedia de Guadalajara. http://enwada.es/wiki/Modesto_Bargall\%C3\%B3_Ardevol (consultado el 8-5-2020).

39 Guadaqué, «El IES Domínguez Ortiz de Azuqueca reconoce la labor docente de la familia de Modesto Bargalló», Guadaqué. https:/www.guadaque.com/provincia-guadaque/el-ies-dominguez-ortiz-de-azuqueca-reconoce-la-labor-docente-de-la-familia-de-modesto-bargallo (consultado el 8-52020).

40 Véase, por ejemplo: Thomas Söderqvist, The Historiography of Contemporary Science, Technology and Medicine. Writing recent science (Nueva York: Routledge, 2006); Mary Jo Nye, «Scientific biography: History of Science by Another Means?», Isis 97, 2 (2006): 322-329. 
nuevo contexto. Sin embargo, tal y como se puede colegir de las líneas anteriores, la biografía de Bargalló en España también se ha visto afectada por el bios y el ergon del contexto mexicano. En primer lugar, porque los estudios biográficos sobre Bargalló han dirigido su mirada a sus años en España desde el conocimiento de su ulterior trayectoria en México, lo que ha dado lugar a que ciertas cuestiones propias de sus años en España no hayan sido todavía objeto de estudio. En segundo lugar, porque el presente relato biográfico ha incorporado información biográfica inédita procedente de algunas fuentes primarias y de archivo en las que Bargalló narra desde México algunos aspectos de sus años en España. Dichas fuentes han sido analizadas desde la cautela que se impone al considerar el papel creativo y selectivo de la memoria, tanto más en una experiencia tan traumática como fue el exilio forzado por la Guerra Civil, que le obligó a abandonar «la tierra donde dormían el sueño eterno sus amados padres» y que nunca volvió a pisar. ${ }^{41}$

\section{UNA MIRADA ANALÍTICA A LA BIOGRAFÍA DE MODESTO BARGALLÓ EN ESPAÑA (1894-1939)}

\section{Orígenes sociales y primeros estudios (1894-1912)}

\section{Primeros años (1894-1904)}

Modesto Bargalló Ardévol nació el 4 de enero de 1894 en Sabadell en el seno de una familia de dilatada tradición docente. ${ }^{42}$ La familia Bargalló Ardévol contaba entonces con tres miembros: Miguel Bargalló Sentís, natural de Duesaigües (Tarragona), Concepción Ardévol Mora, natural de Lloá (Tarragona) y el primogénito del matrimonio, Miguel Bargalló Ardévol, quien había nacido el 24 de agosto de 1892 en San Sadurní d’Anoia (Barcelona). Los orígenes sociales de Modesto Bargalló se revelan de este modo como un factor que contribuyó a que se familiarizase con el ejercicio de la docencia desde una edad temprana. Su

\footnotetext{
41 Bargalló, Trabajos, artículos y apuntes (1940-1972), 533.

${ }^{42}$ En una entrevista publicada en 2014, Luisa Bargalló Porrera, hija de Modesto Bargalló, afirmaba que su padre (Modesto Bargalló Ardévol), su abuelo (Miguel Bargalló Sentís) y su bisabuelo (Miguel Bargalló Pellicer) fueron maestros. Dicha afirmación se recoge a partir del minuto 7.00 de la entrevista: YouTube, «Maestra María Luisa Bargalló», https://www.youtube.com/watch?v=zIrklcbHlcg (consultado el 10-5-2020).
} 
madre, Conchita (como solía referirse a ella en algunas de las dedicatorias de sus libros), fue maestra en escuelas de diferentes localidades catalanas como Las Cabañas y Rojals. Su labor se inscribió en un contexto en el que había aumentado la presencia de maestras en la enseñanza primaria, siendo una de las escasas oportunidades de movilidad laboral para las mujeres. ${ }^{43}$

Más información biográfica se conoce sobre el padre de los hermanos Bargalló Ardévol. Miguel Bargalló Sentís obtuvo plaza como maestro nacional en San Sadurní d'Anoia en 1892, donde nació el mayor de los hermanos. En 1893 fue destinado a Sabadell, donde un año más tarde nació el segundo de los hermanos y protagonista de este trabajo. En 1910, Conchita Ardévol Mora y Miguel Bargalló Sentís se establecieron en Reus. En este municipio catalán forjaron una relevante notoriedad, materializada en el hecho de que se les presentase como "reusencs d'estima i voluntat» en el Diccionari Biogràfic de Reusencs. En 1912 el padre de los hermanos Bargalló fue nombrado vocal de la Junta Local de Instrucción Pública y organizó la Caixa Escolar d'Estalvis con el objetivo de fomentar el ahorro entre los jóvenes. En esta época también creó una escuela de primera enseñanza que se localizó en el domicilio sito en el número 35 del rabal reusense de Santa Anna. En el mismo falleció Conchita Ardévol en 1926.44 Miguel Bargalló fallecerá dos años después, el 8 de noviembre de 1928.45

Además del ejercicio de la enseñanza primaria, Miguel Bargalló Sentís ocupó otros cargos destacados en el ámbito pedagógico de la época. Fue presidente de la Federación de Maestros de Cataluña y director de El Magisterio Tarraconense. Bargalló Sentís fue también profesor en la Escuela Normal de Maestros de Tarragona, una de las primeras escuelas normales creadas en España. Cuando las enseñanzas de magisterio fueron asimiladas por el Instituto de Tarragona, fue profesor de Derecho y Legislación Escolar en este centro. ${ }^{46}$ Su quehacer como maestro,

\footnotetext{
43 Teresa González Pérez, «Aprender a enseñar en el siglo XIX: La formación inicial de las maestras», Revista Electrónica Interuniversitaria de Formación del Profesorado 14, 4 (2010): 133-143.

44 «Bargalló Sentís, Miquel», en Diccionari Biogràfic de Reusencs, ed. Josep Olesti Trilles (Reus: Ajuntament de Reus, 1991): 95.

45 Modesto Bargalló Ardévol, «Necrológicas», Faraday 8 (1928): 10.

46 Juana Noguera Arrom, La Escuela Normal de Tarragona, 1843-1931. Cien años de vida de una escuela normal (Barcelona: Publicaciones de la Universidad de Barcelona, 1984), 115.
} 
director editorial y docente normalista le revela como un claro testigo directo de la pedagogía de la época. No en vano, ha sido señalado como "uno de esos maestros inquietos, conocedores de las innovaciones educativas propias de su tiempo, que asistían a las asambleas y cursos de perfeccionamiento y que intentaban aplicar en sus escuelas los cambios metodológicos». ${ }^{47}$ En esta línea permitía apuntar las referencias de Modesto Bargalló a sus progenitores en algunas de sus obras, quien afirmará que aprendió «desde niño a amar a las plantas, los bichos y las piedras», en clara sintonía con un aprendizaje práctico y observacional de la naturaleza propio de diversas corrientes de la escuela nueva. ${ }^{48}$ Bargalló también se referirá a sus progenitores como «sus primeros maestros». ${ }^{49} \mathrm{Si}$ bien estas palabras pudieran parecer fruto del afecto y consideración de un hijo hacia sus padres, el magisterio al que se refería Bargalló fue literal, ya que sus progenitores fueron a su vez responsables de su formación durante sus primeros años:

Recibí la enseñanza de mis padres. De las primeras letras, las primeras nociones, los elementos, y en general, cultura general. Y asistí muy poco a la escuela. Además, no era quizá muy buen asistente, junto con mi hermano, hacíamos muchos novillos. Y el maestro [...] que estaba un poquito, yo no digo regañado, pero un poco... en cierto modo un poco enemistado con mi papá, pues no se atrevía a decir que no íbamos a la escuela porque podía creer, ¿verdad?, que es que mi papá quien no nos mandaba ya allá. No, no éramos muy buenos estudiantes... ${ }^{50}$

Todo ello permite señalar la importancia de los orígenes sociales y la tradición docente de su familia como factores que contribuyeron a que se familiarizase con la docencia y tuviese contacto como discente con la renovación pedagógica antes de iniciar su formación como docente. Al mismo tiempo, la vinculación con Reus, donde sus padres lograron una destacada visibilidad, resultará especialmente relevante para su quehacer editorial, como se mostrará.

\footnotetext{
47 Noguera Arrom, La Escuela Normal de Tarragona, 150.

${ }^{48}$ Dedicatoria incluida en: Modesto Bargalló, La vida de las plantas (Reus: Ediciones Sardá, 1920).

49 Dedicatoria incluida en: Bargalló, Trabajos, artículos y apuntes (1940-1972).

50 Mantecón, «Entrevista a Modesto Bargalló», 2.
} 


\section{Bachiller y maestro (1904-1911)}

Tras sus estudios primarios, Bargalló estudió el bachillerato en el Instituto General y Técnico de Tarragona entre 1904 y 1910. Durante estos años, el currículo de bachillerato estuvo regido por el conocido como plan Bugallal, en referencia al ministro de Instrucción Pública y Bellas Artes Gabino Bugallal Araújo. Así, en su paso por el instituto tarraconense, Bargalló cursó materias tanto humanísticas como científicas y artísticas, como se puede observar en la tabla 1. Durante los seis cursos que Bargalló estudió en este centro fueron directores Juan Ramonacho Clerch (hasta 1905), Domingo Sáenz Barnés (entre 1905 y 1907) y Ángel Soler Galtés (desde 1907). ${ }^{51}$ El propio Bargalló mencionará a Ramonacho como uno de sus queridos maestros en la dedicatoria de su trabajo recopilatorio publicado en México en 1973, donde también incluyó a otro docente de este centro, Martín Navarro Flores, profesor de Psicología, Lógica y Ética. ${ }^{52}$

Ya en el exilio, Bargalló recodará el instituto como «un buen centro» que «tenía buenos maestros que cumplían muy bien», como Juan Ramonacho, "un magnífico profesor de Matemáticas».53 Ramonacho, quien fue compañero de claustro del padre de Modesto Bargalló cuando ejerció en el Instituto de Tarragona, llevó a cabo una intensa actividad realizando medidas meteorológicas en el patio del instituto cuando el joven Bargalló estudiaba el bachillerato. ${ }^{54}$ Se trata de una práctica que el propio Bargalló llevará a cabo en sus años como docente en la Escuela

\footnotetext{
51 José María Recasens y José Sánchez Real. El Instituto de Enseñanza Media "Antonio Martí y Franqués» de Tarragona (1845-1965). Contribución al conocimiento de la historia de sus primeros 120 años (Tarragona: Ayuntamiento de Tarragona, 1969).

52 Dedicatoria incluida en: Bargalló, Trabajos, artículos y apuntes (1940-1972).

53 Mantecón, «Entrevista a Modesto Bargalló», 3.

54 Una labor de más de una década de anotaciones diarias que se materializó en el reconocimiento de la estación meteorológica del Instituto General y Técnico de Guadalajara como oficial por el Instituto Geográfico y Estadístico en 1912: Recasens Comas y Sánchez Real, El Instituto de Enseñanza Media "Antonio Martín y Franqués», 86. Cabe destacar que la instalación de estaciones meteorológicas en los institutos de segunda enseñanza constituyó una empresa de marcado carácter político que buscaba promover la extensión del sistema métrico decimal y el uso de instrumentos estandarizados, lo que resultó clave en la vertebración administrativa y técnica del Estado; a la par que los diferentes agentes implicados (profesorado y alumnado) adquirían formación científico-técnica y el centro escolar forjaba una notable proyección social. Sobre esta cuestión, véase: Guijarro Mora, Víctor, Artefactos y acción educativa. La cultura del objeto científico en la enseñanza secundaria en España (1845-1930) (Madrid: Dykinson, 2018), 133-134.
} 
Normal de Maestros de Guadalajara, en cuyo patio interior instaló una modesta estación meteorológica. ${ }^{55}$

Tabla 1. Plan de estudios de bachillerato cursado por Modesto Bargalló

\begin{tabular}{|l|l|}
\hline Curso & Asignaturas \\
\hline $\begin{array}{l}\text { Primero } \\
(1904-1905)\end{array}$ & $\begin{array}{l}\text { Lengua Castellana, Geografía General y de Europa, Nociones y } \\
\text { ejercicios de Aritmética y Geometría, Religión, Caligrafía }\end{array}$ \\
\hline $\begin{array}{l}\text { Segundo } \\
(1905-1906)\end{array}$ & $\begin{array}{l}\text { Lengua Latina, Geografía Especial de España, Aritmética, } \\
\text { Religión, Gimnasia }\end{array}$ \\
\hline $\begin{array}{l}\text { Tercero } \\
(1906-1907)\end{array}$ & $\begin{array}{l}\text { Lengua Latina, Lengua Francesa, Historia de España, Geometría, } \\
\text { Religión, Gimnasia }\end{array}$ \\
\hline $\begin{array}{l}\text { Cuarto } \\
(1907-1908)\end{array}$ & $\begin{array}{l}\text { Preceptiva Literaria y Composición, Lengua Francesa, Historia } \\
\text { Universal, Álgebra y Trigonometría, Dibujo }\end{array}$ \\
\hline $\begin{array}{l}\text { Quinto } \\
(1908-1909)\end{array}$ & $\begin{array}{l}\text { Psicología y Lógica, Elementos de Historia General de la } \\
\text { Literatura, Física, Fisiología e Higiene, Dibujo }\end{array}$ \\
\hline $\begin{array}{l}\text { Sexto } \\
(1909-1910)\end{array}$ & $\begin{array}{l}\text { Ética y Rudimentos de Derecho, Historia Natural, Agricultura y } \\
\text { Técnica Agrícola e Industrial, Química General }\end{array}$ \\
\hline
\end{tabular}

Fuente: Gaceta de Madrid, 259 (16 de septiembre de 1903): 2391-2392.

En su paso por el instituto tarraconense, Bargalló asistió a las clases de Psicología y Lógica de Martín Navarro. Años después, cuando Bargalló publique su primer manual de química en 1919, mencionará las Nociones de Psicología del que fue su profesor como una obra de interés para conocer "el valor de las leyes, teorías y de la ciencia». ${ }^{56}$ Muchos años después, contando ya con una dilatada tradición docente, Bargalló citará el Compendio de Lógica de Navarro como obra de referencia en su Metodología de las Ciencias Naturales y de la Agricultura. ${ }^{57}$

Durante sus años en el instituto, Bargalló demostró poseer una especial destreza y habilidad para el dibujo, tal y como atestiguan las calificaciones de Matrícula de Honor obtenidas en las materias de Dibujo I y

\footnotetext{
55 Pozo Andrés, Segura Redondo y Díez Torre, Guadalajara en la historia del magisterio español (1839-1939), 256-257.

56 Modesto Bargalló y Marcelino Martín, Manual de Química (Reus: Ediciones Sardá, 1919), 379.

57 Modesto Bargalló, Metodología de las Ciencias Naturales y de la Agricultura (Reus: Ediciones Sardá, 1932), 36.
} 
Dibujo II. ${ }^{58}$ Se trata de una destreza que él mismo pondrá en valor en sus años como docente y que tendrá especial relevancia en su quehacer editorial en España y México. Especial mención merece el hecho de que el célebre químico norteamericano Linus Pauling, galardonado con el Premio Nobel de Química en 1954, destacase de una de las obras de Bargalló su «especial buen uso del dibujo», lo que convertía su obra en «una excelente introducción a la química general».59

Todo ello apunta a sus estudios de bachillerato como años de contacto con diversos conocimientos culturales generales y ciertas prácticas pedagógicas, destrezas, autores y obras que le serán de interés en su ulterior labor docente y editorial. El 22 de septiembre de 1910, Bargalló finalizó los estudios de bachillerato con la calificación final de sobresaliente. ${ }^{60}$ Un año después obtendrá el título de maestro (elemental y superior) por la Escuela Normal de Maestros de Huesca. ${ }^{61}$ Se trataba de una situación frecuente en la época, pues los bachilleres podían obtener el título de magisterio cursando únicamente las materias de Pedagogía y Religión y Moral, a la par que debían realizar prácticas pedagógicas. ${ }^{62} \mathrm{Si}$ bien esta formación pedagógica puede considerarse insuficiente, fue ampliamente compensada durante sus años en Madrid.

\section{Formación normalista y universitaria (1912-1931)}

\section{La formación de un profesor normalista de ciencias}

No se conoce con exactitud el momento en que Bargalló se trasladó a Madrid, lo cual debió de ocurrir tras obtener el título de magisterio en 1911 y antes del inicio de su formación normalista en 1912. Algunos

\footnotetext{
${ }_{58}$ Estas materias le fueron convalidadas en su acceso a los estudios de licenciatura en 1913. Las calificaciones aparecen así recogidas en: «Expediente de Modesto Bargalló Ardévol (1913-1931)», Universidades 5301/11, Archivo Histórico Nacional (AHN).

59 Traducción del original en inglés: «Carta de Linus Pauling a Modesto Bargalló», 15 de diciembre de 1958, Archivo de la Oregon State University. La carta original se puede consultar en este enlace: http:// scarc.library.oregonstate.edu/coll/pauling/calendar/1958/12/15-xl.html (consultado el 15-7-2020).

60 «Expediente de Modesto Bargalló Ardévol (1913-1931)», Universidades 5301/11, Archivo Histórico Nacional (AHN).

${ }^{61}$ Mayagoitia, Villareal y Bolívar, «Modesto Bargalló: su vida y su obra», IX.

62 Segura, Díez Torre y Pozo Andrés, «Aportaciones a la didáctica de las ciencias naturales de Modesto Bargalló», 215.
} 
recuerdos de Bargalló en sus años en México, hasta ahora inéditos, han permitido conocer algo más de este periodo. Así, a sus 85 años Bargalló recordará que en Madrid fue «una persona privilegiada» y que antes de ingresar en la Escuela de Estudios Superiores del Magisterio en 1912, tuvo «primero un año de preparación» en el que fue «auxiliar del colegio de sordomudos». Allí vivió un periodo de «libertad ordenada», contando con comida y «toda clase de servicios» por parte de las «muchachas sordomudas» que «cuidaban muy bien la ropa y todo».63

Contando con 18 años en septiembre de 1912, Bargalló cumplía los requisitos establecidos por el plan de 1911 para ingresar en la Escuela de Estudios Superiores del Magisterio: tener una edad comprendida entre 18 y 36 años; y haber aprobado la reválida del grado de maestro superior de primera enseñanza. Sin embargo, todavía debía realizar las pruebas de ingreso a la institución madrileña donde se formaría como profesor normalista de ciencias, junto a otros profesores normalistas de las secciones de letras y labores y a futuros inspectores. Las pruebas de ingreso se realizaron entre el 11 y el 25 de septiembre de 1912 y consistieron en tres ejercicios. En primer lugar, una prueba de lectura y traducción de un texto del francés al castellano, sin poder hacer uso de diccionario. En segundo lugar, la redacción de un texto sobre una cuestión pedagógica, en el que se valoraba tanto el contenido, como la claridad y el estilo. Finalmente, el tercer ejercicio para la sección de ciencias consistía en una prueba oral sobre una cuestión científica y un ejercicio práctico sobre matemáticas, dibujo o ciencias fisiconaturales. ${ }^{64}$ Superadas las pruebas de ingreso, Bargalló se matriculó entre el 26 y el 30 de septiembre para comenzar las clases el 1 de octubre.

Bargalló recordará esta institución como «una escuela realmente magnífica, con los mejores profesores casi que entonces había en España», reconociendo que muchos estudiantes universitarios "tenían un poco de envidia burlona» de quienes estudiaban en «el flamante edificio de la calle de Montalbán». ${ }^{65}$ Bargalló se formó como docente normalista de ciencias en la Escuela de Estudios Superiores del Magisterio entre

\footnotetext{
63 Mantecón, «Entrevista a Modesto Bargalló», 9.

${ }^{64}$ Gaceta de Madrid 258, 15 de septiembre de 1911: 715-716.

65 Mantecón, «Entrevista a Modesto Bargalló», 7.
} 
1912 y 1915, donde cursó las materias que se recogen en la tabla 2. Durante estos tres cursos de formación, la escuela se vio afectada por tres planes de estudio diferentes. ${ }^{66}$ El plan de 1911 introdujo un aspecto curricular especialmente destacable, que no fue mantenido por el plan de 1914. Así, con la entrada en vigor del plan de 1911 las materias científicas cambiaron de denominación pasando de denominarse Física, Química, Historia Natural o Matemáticas a las correspondientes Metodologías. Se trata de una clara apuesta por fomentar la formación del futuro docente normalista no únicamente en cuestiones científicas, sino también en las estrategias didácticas para su enseñanza.

No obstante, pese a los cambios nominativos, las clases de la sección de ciencias podrían haber tenido un enfoque más culturalista que metodológico. En este sentido apunta que la mayoría de docentes de la sección de ciencias fuesen científicos de reputado prestigio (sobre todo en el caso de los docentes de historia natural) o con cierta trayectoria en el ámbito de sus respectivas disciplinas científicas, pero sin destacadas publicaciones o contribuciones de índole pedagógico. ${ }^{67}$ No obstante, Bargalló pudo asistir a las clases de historia natural de Emilio Ribera Gómez, doctor en ciencias con una trayectoria de más de treinta años como profesor de instituto y numerosas estancias en el extranjero. ${ }^{68}$ También asistió a las clases de física de Vicente Vera López, doctor en ciencias y auxiliar de instituto, y de química de Pablo Martínez Strong, doctor en ciencias y maestro superior, quien proporcionó a Bargalló algunos materiales que le fueron útiles durante su posterior labor educativa. ${ }^{69}$

\footnotetext{
${ }_{66}$ Antonio Molero y María del Mar del Pozo Andrés, Un precedente histórico en la formación universitaria del profesorado español. La Escuela de Estudios Superiores del Magisterio (1909-1936) (Madrid: Universidad de Alcalá de Henares, 1989).

${ }^{67}$ Sobre esta cuestión, véase: Bernal Martínez, Renovación pedagógica y enseñanza de las ciencias, 104-107.

${ }^{68}$ Santiago Aragón Albillos, «Los premios Ribera: el mecenazgo privado en los tiempos de la institucionalización de la actividad científica en España», en Aulas modernas. Nuevas perspectivas sobre las reformas de la enseñanza secundaria en la época de la JAE, ed. Leoncio López-Ocón (Madrid, Dykinson-Universidad Carlos III, 2014), 47-75.

${ }^{69}$ A principios de 1920, Bargalló construirá con dos de sus estudiantes de la Escuela Normal de Maestros de Guadalajara un modelo de dinamo inspirado en el modelo que les proporcionó Pablo Martínez Strong. Dicho proceso de construcción fue explicado y publicado por los estudiantes en: Federico Moreno y Fernando Suay, «Prácticas de física: Construcción de un pequeño motor eléctrico, tipo dinamo», Revista de Escuelas Normales, 24 (1925): 137-139.
} 
Tabla 2. Materias cursadas por Modesto Bargalló en sus años de formación en la Escuela de Estudios Superiores del Magisterio

\begin{tabular}{|c|c|c|}
\hline Curso y plan & Materias comunes & $\begin{array}{l}\text { Materias de la Sección de } \\
\text { Ciencias }\end{array}$ \\
\hline $\begin{array}{l}\text { Primero } \\
1912-1913 \\
\text { (plan 1911) }\end{array}$ & $\begin{array}{l}\text { Pedagogía fundamental } \\
\text { Organización, Legislación y } \\
\text { Administración Escolar } \\
\text { Psicología, Lógica y Ética aplicada a } \\
\text { la Pedagogía } \\
\text { Fisiología e Higiene } \\
\text { Inglés o Alemán } \\
\text { Trabajos Manuales } \\
\text { Religión y Moral (no obligatoria) } \\
\text { Música } \\
\text { Dibujo } \\
\text { Educación Física }\end{array}$ & $\begin{array}{l}\text { Metodología de las } \\
\text { Ciencias Matemáticas } \\
\text { Metodología de las } \\
\text { Ciencias Físicas } \\
\text { Metodología de la } \\
\text { Historia Natural }\end{array}$ \\
\hline $\begin{array}{l}\text { Segundo } \\
1913-1914 \\
\text { (plan 1913) }\end{array}$ & $\begin{array}{l}\text { Historia de la Pedagogía } \\
\text { Pedagogía para Anormales } \\
\text { Derecho Usual y Economía social } \\
\text { Inglés o Alemán } \\
\text { Trabajos Manuales }\end{array}$ & $\begin{array}{l}\text { Metodología de las } \\
\text { Ciencias Matemáticas } \\
\text { Metodología de las } \\
\text { Ciencias Químicas } \\
\text { Metodología de la } \\
\text { Historia Natural }\end{array}$ \\
\hline $\begin{array}{l}\text { Tercero } \\
1914-1915 \\
\text { (plan 1914, } \\
\text { disposición } \\
\text { transitoria) }\end{array}$ & \multicolumn{2}{|c|}{$\begin{array}{l}\text { Higiene escolar } \\
\text { Técnica de Inspección } \\
\text { Realización de prácticas pedagógicas dirigidas por los profesores y } \\
\text { profesoras de pedagogía fundamental y de anormales. Dichas } \\
\text { pruebas debían desarrollarse en la EESM, las escuelas públicas y } \\
\text { normales de Madrid con las que existiese acuerdo. Los alumnos } \\
\text { debían llevar anotaciones diarias de los sus trabajos y } \\
\text { observaciones realizados hasta el } 15 \text { de mayo, teniendo que } \\
\text { depositar una copia en la EESM antes del } 21 \text { de mayo. }\end{array}$} \\
\hline
\end{tabular}

Fuente: Elaborada a partir de los Reales Decretos por los que se establecieron los planes de 1911, 1913 y 1914, respectivamente: Gaceta de Madrid, 258 (15 de septiembre de 1911): 712-716; Gaceta de Madrid, 26 (26 de enero de 1913): 210; Gaceta de Madrid, 245 (2 de septiembre de 1914): 567-573.

Pero si hubo dos profesores de la Superior que Bargalló recordará especialmente fueron Mercedes Sardá Uribarri, profesora de Organización, Legislación y Administración Escolar, y Luis de Zulueta, profesor de Historia de la Pedagogía. ${ }^{70}$ El paso de Bargalló por las aulas de estos

\footnotetext{
${ }^{70}$ Les recordaba como uno de sus «queridos maestros» en la dedicatoria incluida en: Bargalló, Trabajos, artículos y apuntes (1940-1972).
} 
docentes revela la relevancia de los postulados de la Institución Libre de Enseñanza en su formación. ${ }^{71}$ Especial mención merece Luis de Zulueta, quien en la biografía que Modesto Bargalló incluyó en su obra recopilatoria en México aparecerá mencionado como uno de los tres docentes que «influyeron en alto grado en la orientación de su futura labor didáctica». ${ }^{72}$ En las clases de Zulueta, Bargalló pudo experimentar en primera persona la importancia de entender la enseñanza como un proceso de investigación. El mismo Bargalló posiblemente realizó un trabajo de investigación bajo las orientaciones de Zulueta sobre un tema histórico. En concreto, una investigación sobre la labor legislativa de las Cortes españolas en los años 1820-1823 que dio lugar a un trabajo presentado en la sección de Ciencias Sociales del Congreso de la Asociación Española para el Progreso de las Ciencias de Sevilla de 1917 y del que se publicó un extracto en el Boletín de la Institución Libre de Enseñanza (BILE) ese mismo año. ${ }^{73}$ Bargalló fue así conocedor directo del credo pedagógico renovador de la época a través de las clases de Zulueta, siendo educado en la importancia de adecuar la enseñanza al estudiante y de concebir esta como un diálogo entre discentes y docentes. ${ }^{74}$

Los otros dos docentes que «influyeron en alto grado en la orientación de su futura labor didáctica» fueron Manuel Bartolomé Cossío y Edmundo Lozano. ${ }^{75}$ En sus años en Madrid, Bargalló asistió a los cursos de pedagogía y de metodología de las ciencias fisicoquímicas que estos docentes impartían, respectivamente, en el Museo Pedagógico Nacional. Ya anciano, Bargalló admitirá que tenía consigo en México algunas disertaciones pedagógicas que estaban «casi copiadas textualmente de los apuntes que tomaba del señor Cossío», a quien recordaba como «un hombre admirable que explicaba con claridad meridiana, un hombre

\footnotetext{
${ }^{71}$ Cabe destacar que Mercedes Sardá fue la hija del pedagogo catalán Agustín Sardá Llabería, amigo de Francisco Giner de los Ríos.

72 Mayagoitia, Villareal y Bolívar, «Modesto Bargalló: su vida y su obra», IX.

73 Se publicó en dos partes: Modesto Bargalló, «Labor legislativa sobre enseñanza de las Cortes españolas, 1820-1825», BILE, 687(1917): 174-181; e ibíd., 688 (1917): 213-216.

${ }_{74}$ Para un testimonio de una exalumna de Zulueta en la Escuela de Estudios Superiores del Magisterio (Julia Pérez Seoane, egresada de la Escuela de Estudios Superiores del Magisterio en 1916), véase: Salvador Ferrer Culubret y Maura, Una institución docente española: La Escuela de Estudios Superiores del Magisterio, 1909-1932 (Madrid: Cedesa, 1973), 257.

75 Mayagoitia, Villareal y Bolívar, «Modesto Bargalló: su vida y su obra», IX.
} 
extraordinario». ${ }^{76}$ Bargalló recordará entonces la asistencia durante un año a los cursos del célebre pedagogo y director del mencionado Museo, los cuales tuvieron una gran afluencia. En consonancia con este testimonio, el proyecto pedagógico bargalliano se revelará profundamente deudor de estos años de formación en los que aprendió, entre otros aspectos, la importancia de huir de costosos artefactos e instrumentos para fomentar la enseñanza a partir de la construcción de los mismos. ${ }^{77}$

Las clases de Edmundo Lozano serán también fundamentales para la labor docente que Bargalló estaba a punto de iniciar al término de sus años en Madrid. No sorprende así que dedicase a Lozano su primer manual de química "en testimonio de admiración y cariño». ${ }^{78}$ Bargalló hizo clara apropiación activa de la concepción de la promoción del hábito científico como fin fundamental de la enseñanza de las ciencias defendida por Lozano, entendiéndolo como un proceso de investigación basado en la observación y la experimentación. Cabe destacar que entre las influencias reconocidas por el propio Edmundo Lozano se encontraba la obra del químico-pedagogo alemán Wilhelm Ostwald, cuyo Grundlinien der anorganischen Chemie le inspiró para la preparación de sus cursos de química en el Museo Pedagógico Nacional. ${ }^{79}$ Es por ello que es posible apuntar hacia los cursos de Lozano como un punto de contacto significativo de Bargalló con la obra de Ostwald, cuyos Elementos de Química tradujo al castellano pocos años después. Como se mostrará en próximos epígrafes, la obra de este químico-pedagogo tuvo un papel destacado en el quehacer docente de Bargalló.

Las clases de Zulueta, Cossío y Lozano no fueron los únicos puntos de contacto de Bargalló con las ideas de la Institución Libre de Enseñanza durante sus años en Madrid. En la capital, Bargalló se alojó junto a su hermano Miguel en la célebre Residencia de Estudiantes. ${ }^{80}$ Allí

\footnotetext{
${ }^{76}$ Mantecón, «Entrevista a Modesto Bargalló», 38.

77 Véase la edición realizada por Eugenio Otero Urtaza de: Manuel Bartolomé Cossío, El maestro, la escuela y el material de enseñanza y otros escritos (Madrid: Biblioteca Nueva, 2007).

78 Dedicatoria incluida en: Bargalló y Martín, Manual de Química.

${ }^{79}$ Edmundo Lozano, La química de la escuela primaria (Madrid: R. Rojas, 1913), 103-104.

80 Véase: Margarita Sáenz de la Calzada. La Residencia de Estudiantes. Los Residentes (Madrid: Publicaciones de la Residencia de Estudiantes, 2011); y Álvaro Ribagorda. El coro de Babel. Las actividades culturales de la Residencia de Estudiantes (Madrid: Publicaciones de la Residencia de Estudiantes, 2011).
} 
pudo respirar del clima intelectual de la época, del que décadas después recordará a figuras como Miguel de Unamuno, que desde primera hora de la mañana estaba ya rodeado de alumnos, pues «siempre estaba educando». ${ }^{81}$ Bargalló comenzaría él mismo a educar al término de su formación en la Escuela de Estudios Superiores del Magisterio y en el Museo Pedagógico Nacional. Habiendo finalizado sus estudios normalistas con el segundo mejor expediente de la promoción de 1915 en la sección de ciencias, el 25 de junio de 1915 fue nombrado Profesor Numerario de Física, Química, Historia Natural y Agricultura en la Escuela Normal de Maestros de Guadalajara con un sueldo anual de 3000 pesetas. ${ }^{82}$ En este centro Bargalló ejercerá la docencia hasta que fue destinado a la Escuela Normal de Maestros de Cuenca en 1937, con motivo de la Guerra Civil. ${ }^{83}$ Sin embargo, el periodo de docencia 19151937 (también un periodo de gran actividad editorial), se solapó con un periodo de continuación de su formación cursando los estudios de licenciatura en ciencias.

\section{La formación de un licenciado en ciencias}

En 1913 Bargalló inició los estudios de licenciatura en ciencias en la Universidad Central de Madrid, matriculándose en la asignatura Mineralogía y Botánica. Sin embargo, no retomará dichos estudios hasta el curso 1915-1916, siendo ya profesor de escuela normal en Guadalajara. Bargalló cursó estos estudios como alumno libre, acudiendo a Madrid a realizar exámenes en la Facultad de Ciencias y sesiones prácticas en el Museo Nacional de Ciencias Naturales. Su expediente académico se recoge en la tabla 3. Como es posible colegir del mismo, la formación universitaria de Bargalló se centró en el ámbito de las ciencias naturales (mineralogía, zoología, botánica...) lo cual permite explicar sus contribuciones científicas a dichas disciplinas, estudiadas en los últimos años, tal y como se señaló al inicio del presente trabajo.

\footnotetext{
${ }^{81}$ Mantecón, «Entrevista a Modesto Bargalló», 35.

82 Gaceta de Madrid, 185 (4 de julio de 1915): 27.

${ }^{83}$ Gaceta de la República, 273 (25 de agosto de 1937): 792.
} 
Tabla 3. Expediente de Modesto Bargalló como alumno libre de la Facultad de Ciencias de la Universidad Central de Madrid

\begin{tabular}{|l|l|l|}
\hline Asignatura & \multicolumn{1}{|c|}{ Curso } & Calificación \\
\hline Mineralogía y Botánica & $1913-1914$ & Notable \\
\hline Química General & $1915-1916$ & Aprobado \\
\hline Zoología General & $1915-1916$ & Suspenso \\
\hline $\begin{array}{l}\text { Técnica micrográfica e Histología } \\
\text { vegetal y animal }\end{array}$ & $1915-1916$ & Aprobado \\
\hline Física General & $1920-1921$ & Aprobado \\
\hline Zoología General & $1920-1921$ & Aprobado \\
\hline Complementos de Álgebra y Geometría & $1920-1921$ & Aprobado \\
\hline Cristalografía & $1920-1921$ & Aprobado \\
\hline Geografía y Geología Dinámica & $1920-1921$ & Notable \\
\hline Organografía y Fisiología Vegetal & $1920-1921$ & Aprobado \\
\hline Organografía y Fisiología Animal & $1920-1921$ & Aprobado \\
\hline $\begin{array}{l}\text { Zoografía de Animales inferiores y } \\
\text { moluscos }\end{array}$ & $1921-1922$ & Notable \\
\hline Fitografía y Geografía Botánica & $1921-1922$ & Suspenso \\
\hline Zoografía de Articulados & $1921-1922$ & Notable \\
\hline Zoografía de Vertebrados & $1921-1922$ & Aprobado \\
\hline Geología Geonóstica y Estratigráfica & $1929-1930$ & Sobresaliente con opción \\
\hline Fitografía y Geografía Botánica & $1929-1930$ & Sobresaliente con opción \\
\hline Mineralogía Descriptiva & $1929-1930$ & Sobresaliente con opción \\
\hline Antropología & $1930-1931$ & Matrícula de Honor \\
\hline Psicología experimental & $1930-1931$ & Matrícula de Honor \\
\hline Química Biológica & $1930-1931$ & Matrícula de Honor \\
\hline
\end{tabular}

Fuente: Elaborada a partir de: «Expediente de Modesto Bargalló Ardévol (1913-1931)», Universidades 5301/11, Archivo Histórico Nacional (AHN).

Sin embargo, el examen de su expediente también revela un aspecto especialmente significativo: la escasa presencia de materias del ámbito de las ciencias fisicoquímicas. En su formación universitaria, Bargalló 
apenas cursó dos materias de química (Química General y Química Biológica) y una materia de física (Física General), pese a la posibilidad de haber preparado las materias de la especialidad de ciencias fisicoquímicas que también se impartía en la Facultad de Ciencias. ${ }^{84}$ Se trata de un aspecto que permite cuestionar la importancia otorgada a la formación universitaria de Bargalló para la forja de su proyecto pedagógico y su labor editorial, donde la física y la química tuvieron un lugar muy destacado. Su labor, escribiendo múltiples obras sobre física, química y metodología de las ciencias fisicoquímicas o traduciendo textos de dichas ciencias, en modo alguno pueden entenderse entonces como una mera aplicación de su formación científica universitaria. A este respecto, sus estudios de bachillerato, normalistas y en el Museo Pedagógico se revelan como entornos fundamentales en los que pudo adquirir nociones generales de física y química (reforzadas en la preparación de las tres materias de sus estudios universitarios) para su labor profesional.

Al mismo tiempo, esta escasa formación en química en sus estudios universitarios contrasta ampliamente con su presentación como químico frecuente en varios estudios sobre su obra, como se ha señalado. Es posible apuntar a la labor profesional de Bargalló como profesor universitario de química en México como un aspecto que ha podido contribuir a magnificar el papel de su formación universitaria en ciencias en España. A este respecto, el mismo Bargalló afirmará muchos años después:

Confieso que el título nunca me ha servido para nada. Realmente un licenciado en Matemáticas o en Ciencias Naturales, no tiene casi otro camino. No tenía, al menos entonces, otro camino que el del profesorado. Eso, ya lo tenía, no tenía ningún interés en salirme de Guadalajara, teníamos mucho cariño a la Escuela Normal. ${ }^{85}$

Asimismo, al aludir a su formación universitaria, Bargalló daba una explicación ante la ambigua cuestión de su doctorado que encontraremos en varios de los estudios sobre su figura. Así, afirmó que hizo los estudios de doctorado, que "no eran más que tres materias». ${ }^{86}$ Se trata

\footnotetext{
${ }^{84}$ Alfredo Baratas, Antonio Bueno y Pedro Ruíz Castell, 150 años de la Facultad de Ciencias (Madrid: Universidad Complutense de Madrid, 2007).

85 Mantecón, «Entrevista a Modesto Bargalló», 15.

86 Mantecón, «Entrevista a Modesto Bargalló», 14.
} 
de las tres materias del curso 1930-1931 que aparecen en su expediente universitario: Antropología, Psicología Experimental y Química Biológica, pero no de una tesis doctoral que le condujese al título de doctor. No obstante, como se mostrará, aunque el título de licenciado en ciencias no fuese el factor determinante para su labor docente en España, sí le resultó especialmente útil en su quehacer como autor. ${ }^{87}$

\section{Quehacer profesional en España (1915-1939)}

Entre 1915 y 1939, Modesto Bargalló educó en ciencias a cientos de maestros en la Escuela Normal de Maestros de Guadalajara durante 22 años, formó su propia familia junto a Luisa Porrera Llopis, con quien contrajo matrimonio el 19 de febrero de 1920 y tuvo dos hijos (Luisa, nacida en 1921, y Miguel, nacido en 1935); desarrolló una ingente producción impresa como autor y traductor; estuvo al frente del máximo órgano de expresión de su colectivo profesional (la Revista de Escuelas Normales) y desempeñó un papel pionero como editor de una de las primeras publicaciones especializadas en historia y didáctica de las ciencias fisicoquímicas en España (Faraday). Lejos de una mera sucesión de acontecimientos, todas estas facetas convergieron en su biografía, colaborando o rivalizando. Asimismo, hubo lugar para proyectos inacabados y fallidos. Múltiples ejemplos de todos estos aspectos, hasta ahora no abordados o mencionados de soslayo, se ofrecen a continuación.

Bargalló cimentó su proyecto como docente sobre la educación de los futuros maestros en el hábito científico, tal y como promovía Edmundo Lozano y él mismo había experimentado en sus años como discente. En el caso de Bargalló, al concebir el hábito científico como un proceso de investigación científica, su concepción de la enseñanza quedaba íntimamente ligada a su concepción sobre la ciencia. Tal y como es posible colegir de muchos de sus trabajos sobre historia y enseñanza de las ciencias, Bargalló presentaba una concepción de corte comteniano sobre las ciencias, según la cual las mismas se habrían desarrollado en una serie de fases. Dicho desarrollo (filogénico) concordaba con el desenvolvimiento mental del discente (desarrollo ontogénico), como

\footnotetext{
${ }_{87}$ Para un estudio reciente en el que se analiza el proyecto pedagógico bargalliano en detalle desde el marco analítico de los estudios históricos sobre ciencia en las aulas, véase: Moreno Martínez, «Ciencia en las aulas».
} 
promulgaban diversas voces de la época. ${ }^{88}$ De este modo, la adquisición del hábito científico en las aulas pasaba por una serie de fases análogas a las fases históricas por las que las ciencias habían transitado desde sus orígenes: una primera fase cualitativa basada en la observación, una segunda fase cuantitativa basada en la experimentación y una tercera fase en la que el corpus de saberes científico se estructuraba en leyes y teorías. ${ }^{89}$ La ciencia en la escuela primaria debía inscribirse en las dos primeras fases, dejando el estudio de leyes y teorías para la segunda enseñanza:

Partiremos de la observación y experimentación, cualitativas primero (fase empírica), cuantitativas después (fase científica); de las cuales pasaremos a leyes y teorías [...]. De las tres fases del proceso metodológico que acabamos de señalar, solo las dos primeras caben plenamente en la escuela primaria. ${ }^{90}$

Se trata de un argumentario en clara deuda con las enseñanzas de Lozano, quien afirmó que «la primera fase es cualitativa, adaptable al primer grado o curso elemental; las demás son cuantitativas, y en la última se inicia el trabajo de sistematización, estableciendo una ley», no considerando conveniente "pasar más adelante en la escuela primaria, intentando construir teorías». ${ }^{91}$

La importancia de la observación como punto de partida de la investigación que sostiene Bargalló se muestra también profundamente conectada con su admiración por Santiago Ramón y Cajal, quien sostenía que «mucho aprendemos en los libros, pero más aprendemos en la contemplación de la naturaleza». ${ }^{92}$ Bargalló fue un profundo conocedor de la obra cajaliana. Sin embargo, su proyecto pedagógico en modo alguno se

\footnotetext{
${ }^{88}$ Sobre esta cuestión véase: María del Mar del Pozo Andrés, «El movimiento de la escuela nueva y la renovación de los sistemas educativos», Historia de la Educación (Edad Contemporánea), ed. Alejandro Tiana, Gabriela Ossebach y Florentino Sanz (Madrid: UNED, 2009), 189-215.

${ }^{89}$ Para un estudio detallado sobre el papel de la historia de la ciencia en la obra bargalliana, véase: Moreno Martínez, «Ciencia en las aulas».

${ }_{90}$ Modesto Bargalló, Cómo se enseñan las ciencias fisicoquímicas (Madrid: Publicaciones de la Revista de Pedagogía, 1923), 10.

${ }_{91}$ Lozano, La química de la escuela primaria, 4-5.

92 Cita extraída de la edición de 1923 de Los tónicos de la voluntad. Para una edición revisada y comentada, véase la reciente edición de Leoncio López-Ocón: Santiago Ramón y Cajal, Los tónicos de la voluntad. Reglas y consejos sobre investigación científica (Madrid: Gadir, 2018), 83.
} 
cimentó sobre esta en exclusividad. Por el contrario, este solo puede entenderse como resultado de un activo proceso de apropiación y resignificación de ideas y prácticas promovidas por múltiples actores históricos. Además de Lozano y Cajal, el proyecto pedagógico bargalliano también hunde sus raíces en la modestia material y la dimensión práctica de la enseñanza por la que abogó Cossío. Así, a la observación y la experimentación se unía la importancia pedagógica de construir aparatos científicos por parte de los estudiantes. El mismo Bargalló abordó la construcción de múltiples artefactos, que fueron recopilados en su obra El gabinete de física. ${ }^{93}$

Los estudiantes de magisterio de la escuela normal alcarreña afrontaron la construcción de diversos instrumentos científicos en el taller de la misma. En la descripción de su aula que Bargalló realizó en 1925, se indicaba que su aula estaba dotada de un laboratorio de química y un salón de clases, así como de un aula-taller, entonces en construcción. ${ }^{94}$ Quince años después, a su llegada a México, dibujará desde el recuerdo cómo quedó finalmente dicho aula-taller (figura 1).

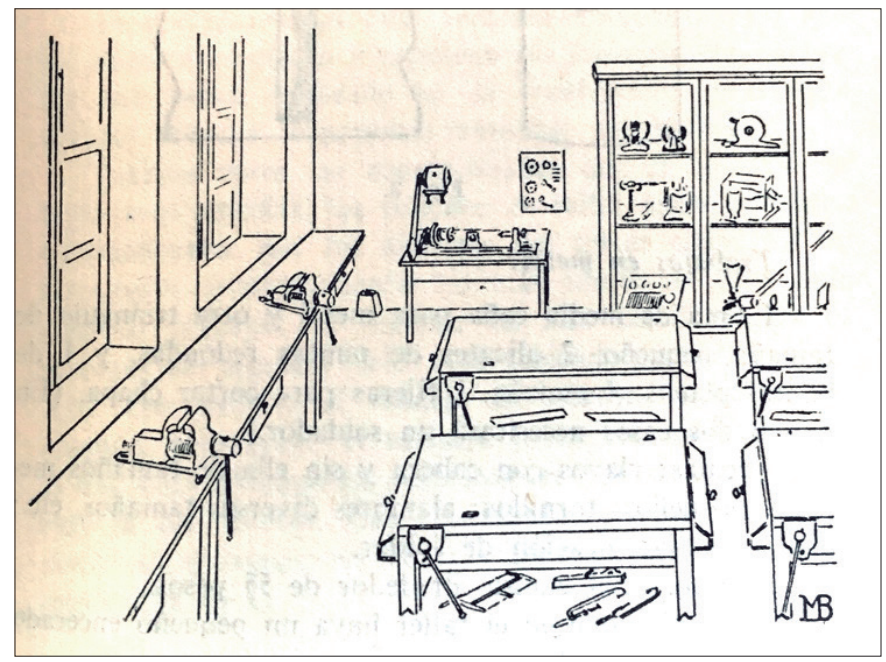

Figura 1. Aula-taller de Modesto Bargalló en la Escuela Normal de Maestros de Guadalajara en la década de 1930.

Fuente: Modesto Bargalló, La física en la escuela primaria (México: EDIAPSA, 1940), 99.

\footnotetext{
${ }_{93}$ Modesto Bargalló, El gabinete de física (Reus: Ediciones Sardá, 1924).

${ }_{94}$ Modesto Bargalló, "Nuestra clase de ciencias físicas», Revista de Escuelas Normales, 30(1925): 333-338.
} 
De las líneas anteriores es posible colegir la convergencia en el ergon bargalliano de su bios como discente. Sin embargo, el ergon bargalliano estuvo integrado por múltiples facetas ora en colaboración ora en tensión. Por ejemplo, en su labor de traducción al castellano de los Elementos de Química del químico-pedagogo alemán Wilhelm Ostwald, Bargalló justificaba el interés de esta obra para los centros de enseñanza en España por permitir «formar, más que un recipiente lleno de datos, una disposición, un hábito para el trabajo científico». ${ }^{95}$ Asimismo, en las líneas introductorias de Ostwald será posible encontrar el paralelismo entre historia de la ciencia -«el desarrollo histórico de los descubrimientos»- y desarrollo del discente -«exigencias de una pedagogía racional» y la «psicología de la edad»- que Bargalló asumió como argumento legitimador de su concepción de la enseñanza basada en promover el hábito científico observando, experimentando y construyendo. ${ }^{96}$

Como autor, Bargalló hizo uso de sus múltiples manuales de ciencias y metodología de las ciencias para hacer circular su proyecto pedagógico más allá de las lindes de su aula, dada la notoria visibilidad que logró alcanzar en el contexto pedagógico de la época. Uno de los factores que se ha señalado para explicar dicha visibilidad fue su papel como director de la Revista de Escuelas Normales desde su creación en enero de 1923 hasta su dimisión en diciembre de 1927; siendo reelegido en junio de 1931, ocupando de nuevo el cargo hasta diciembre de 1932. Sin embargo, también jugó un papel determinante la vinculación de Bargalló al sector editorial, ámbito en el que su padre ya tuvo experiencia y contactos. Así, muchas de las obras de Bargalló en España se publicaron en Ediciones Sardá. Se trata de una editorial sobre la que apenas es posible encontrar información. No obstante, en la entrada destinada a su progenitor en el Diccionari Biogràfic de Reusencs se señalará la vinculación de los hijos de Miguel Bargalló Sentís y Conchita Ardévol Mora con Reus, sede de Ediciones Sardá. En dicha entrada se podrá leer que «la majoria dels seus llibres publicats els imprimia a Reus, en especial a la impremta Diana». ${ }^{97}$ Se trata de la imprenta que figurará en la mayoría de libros

\footnotetext{
95 Cita extraída de la nota del traductor incluida por Bargalló en: Wilhelm Ostwald, Elementos de química (Barcelona: Gustavo Gili, 1917), V.

96 Ostwald, Elementos de química, 2-3.

97 Diccionari Biogràfic de Reusencs, 95.
} 
publicados por Bargalló en Ediciones Sardá. No obstante, a partir de 1934 la sede cambiará de Reus a Guadalajara y Bargalló aparecerá como director de dicha editorial (figura 2). ${ }^{98}$

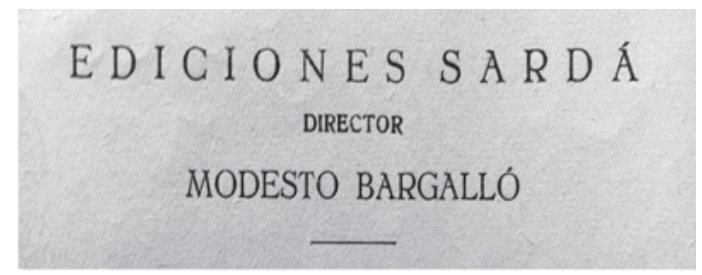

Figura 2. Modesto Bargalló, director de Ediciones Sardá

Fuente: Modesto Bargalló, Problemas de Física y Química (Guadalajara: Sardá, 1936).

Otro factor que resultó especialmente útil a Bargalló para promover la circulación de sus trabajos desde 1931 fue su doble formación científica y pedagógica. Así, la disociación de los estudios de magisterio entre formación cultural en los institutos de segunda enseñanza y formación metodológica en las escuelas normales que establecía el nuevo plan de 1931 fue duramente criticada por Bargalló. El docente normalista vio en ello «la decadencia y la muerte» ${ }^{99}$ de las escuelas normales, pues las clases modestas «que nutren al Magisterio» no podrían cursar la «carísima enseñanza» en los institutos, vaticinando que «la República se quedará sin maestros y la educación popular sin mentores».100 Sin embargo, en el ámbito editorial, Bargalló supo aprovechar esta coyuntura para iniciar la publicación de su colección de manuales de física y química para el plan del bachillerato de 1931 en Ediciones Sardá, en los que desaparecía su estatus de profesor de escuela normal (que sí aparecía en sus obras dirigidas al magisterio) y únicamente se presentará como licenciado en ciencias, requisito compartido con los docentes de segunda enseñanza y potenciales lectores-consumidores de estas obras.

\footnotetext{
${ }_{98}$ Durante la Guerra Civil, las reediciones de varios libros de Bargalló serán publicadas de nuevo en Reus, posiblemente debido al avance del conflicto y el asedio de Guadalajara, dada su proximidad a Madrid.

99 Modesto Bargalló, «Para el Señor Director General: Un mal paso para las Normales», Revista de Escuelas Normales, 90 (1932), 157.

100 Modesto Bargalló, «Al señor ministro», Revista de Escuelas Normales, 92(1932): 35.
} 
Bargalló publicó un total de tres manuales de física y química para el bachillerato en el marco del plan de 1931: Iniciación Experimental en Física y Química (1935), para tercer curso; Nociones de Física y Química (1935), para cuarto curso; y Elementos de Física y Química (1936), para quinto curso. En este último se podía encontrar un próximo título entonces en prensa: Tratado de Física y Química, texto para sexto curso de bachillerato que nunca llegó a ver la luz, posiblemente debido a la Guerra Civil. Esta no es la única obra que Bargalló anunciará en preparación en algunos trabajos publicados y que no llegará a materializarse. Tal es el caso de Ciencias fisiconaturales. Segundo grado, continuación del manual para primer curso de escuela primaria que Bargalló publicó en 1918 en Editorial Calleja, Metodología de la Química y la evolución de esta ciencia, Estudio de animales: acuarios y terrarios en la escuela primaria, Estudio de animales: 10 sencillas disecciones para la escuela primaria, La química en la escuela primaria: 25 prácticas, Los trabajos manuales en la escuela primaria: 50 prácticas, El moblaje complementario de la escuela primaria y Metodología de la Física y de la Química. ${ }^{101}$

Pese a que estas obras nunca vieron la luz, la producción impresa de Bargalló en España se materializó en un manual de química (junto a Marcelino Martín, catedrático del Instituto de Guadalajara y amigo personal de la familia) y otro de física para enseñanzas técnicas, un manual de ciencias de escuela primaria, tres manuales de física y química de bachillerato (plan 1931) y un libro de problemas, tres traducciones, trece obras sobre cuestiones pedagógicas y metodológicas y en torno a un centenar de artículos en diversas revistas. En estos trabajos es posible identificar muchas de las ideas y prácticas pedagógicas de su quehacer docente, como la importancia de la historia de la ciencia (aspecto elogiado en algunas reseñas sobre sus manuales) ${ }^{102}$ o la importancia de una enseñanza práctica de las ciencias que huyese del gabinete prefabricado heredero de la tradición decimonónica. ${ }^{103}$

\footnotetext{
101 Los títulos de estas obras que nunca se llegaron a materializar como tales se pueden localizar como obras «en preparación» en varias de las obras de Bargalló como La vida de las plantas, Metodología de las Ciencias Naturales y de la Agricultura o Manual de Química.

102 Sus obras fueron reseñadas por figuras destacadas como el químico Enrique Moles, el físico Blas Cabrera o el ensayista Eugenio d'Ors, entre otros. En los números de Faraday Bargalló solía incluir fragmentos de estas reseñas como elementos publicitarios de sus manuales.

${ }_{103}$ Para un estudio detallado de esta cuestión, véase: Moreno Martínez, «Ciencia en las aulas».
} 
Sin embargo, la obra impresa de Bargalló también revela las tensiones y contradicciones entre su labor editorial y docente. Así, aunque Bargalló atacó duramente el uso de instrumentos científicos prefabricados, sí recomendaba el uso del microscopio al que dedicó uno de sus manuales, posiblemente, debido a las dificultades para la construcción de dicho instrumento con materiales ordinarios. ${ }^{104} \mathrm{Al}$ mismo tiempo, diferentes empresas de aparatos científicos y educativos aparecerán en el boletín Faraday, proyecto editorial que fundó en 1928 tras la dimisión como director de la Revista de Escuelas Normales y que se mantuvo al menos hasta 1929 (figura 3). ${ }^{105}$
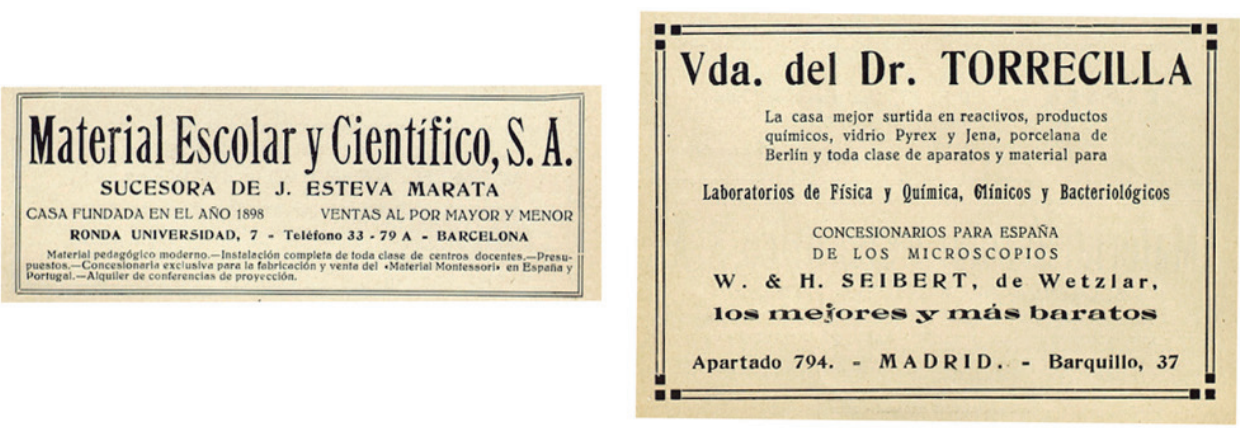

Figura 3. Anuncios publicitarios incluidos en varios números del boletín Faraday.

Fuente: Anuncios localizados en el interior y las contraportadas de varios números de Faraday.

Si bien como docente, Bargalló evitó el uso de materiales prefabricados, en su quehacer editorial sí hicieron acto de presencia posiblemente a fin de facilitar la circulación de sus trabajos, ideas y prácticas más allá del profesorado normalista, donde el uso de este tipo de materiales sí contaba con una dilatada tradición (como la enseñanza secundaria o las enseñanzas técnicas). Para la circulación de sus obras entre el profesorado normalista y los futuros maestros, Bargalló hizo uso de una destreza en la que había manifestado una gran habilidad desde su juventud: el dibujo. Sus líneas de actuación metodológica, por ejemplo, para la realización de ciertas experiencias o la construcción de aparatos de física,

\footnotetext{
104 Modesto Bargalló, El microscopio en la escuela primaria (Reus: Ediciones Sardá, 1933).

105 El análisis del boletín Faraday había permanecido inédito hasta fechas recientes. Para un estudio de las relaciones entre historia y didáctica de las ciencias a partir de este boletín, véase: Moreno Martínez, «Ciencia en las aulas».
} 
se articularon en sus obras en forma de textos descriptivos (donde se detallaban procedimientos, herramientas, materiales, precios, recomendaciones de uso, instrucciones en caso de mal funcionamiento, etc.) e ilustraciones (a veces acompañadas de fotografías) que él mismo realizó. Esta estrategia resultó clave para facilitar la recepción y adaptación de las prácticas propuestas por Bargalló en las escuelas de la época, tratando de compensar tanto la falta de formación científica de muchos maestros, como la componente tácita inherente a la reproducción de prácticas científicas y pedagógicas.

Todo ello contribuyó a hacer de Bargalló una figura destacada en la educación científica del primer tercio del siglo XX. Sin embargo, su trayectoria no estuvo exenta de proyectos fallidos. Tal es el caso de la pensión que en 1928 solicitó a la Junta de Ampliación de Estudios e Investigaciones Científicas (JAE), pero que no logró obtener. Bargalló pretendía dedicar el curso 1928-1929 a preparar una monografía sobre la génesis histórica de la teoría atómico-molecular y sus implicaciones para la enseñanza. Para ello solicitó permanecer ocho meses en París (del 1 de noviembre al 30 de junio de 1929) con posibilidad de realizar traslados a Londres y a Berlín. De nada sirvieron las palabras de Daniel Carretero Riosalido como director de la escuela normal alcarreña donde destacaba la labor docente de Bargalló guiada por «el amor a la enseñanza» y «horas de trabajo extraordinarias»; ni sus conocimientos de alemán, francés, italiano e inglés (además del castellano y catalán como lenguas maternas) que constaban en el informe de solicitud. ${ }^{106}$

Durante los primeros meses de 1928, Bargalló debió conocer el estado desfavorable de su pensión, lo que le llevó a escribir a Santiago Ramón y Cajal, quien le respondió el 2 de junio de 1928 justificando que, dada su mala salud, no había podido enterarse de «la suerte de su solicitud». Cajal confesaba que no asistía a la Junta (JAE) desde hacía 2 años y que el verdadero presidente era Ramón Menéndez Pidal. El premio Nobel se despedía de Bargalló con un «le quiere su viejo y achacoso amigo», ${ }^{107}$ lo cual muestra la cordialidad y cierta proximidad entre Cajal y

\footnotetext{
106 El informe que acompañó la solicitud de pensión de Bargalló a la JAE se puede consultar en: «Expediente de Modesto Bargalló Ardévol», JAE 16/103, Archivo de la Junta de Ampliación de Estudios e Investigaciones Científica (JAE).

107 "Carta de Santiago Ramón y Cajal a Modesto Bargalló», 2 de junio de 1928, Epistolario de Santiago Ramón y Cajal, MSS/22110/27, Biblioteca Nacional de España (BNE).
} 
Bargalló. ${ }^{108}$ Todo ello revela que más allá del respeto y admiración intelectual, Bargalló encontró en Cajal un nodo relevante para su red de influencias, que no siempre dio los frutos deseados. Desde esta óptica, no sorprende que Faraday se inscribiese en el periodo 1928-1929, años en los que Bargalló pretendía centrarse especialmente en la historia de la ciencia y sus usos para la enseñanza como pone de manifiesto la fallida solicitud de pensión a la JAE. Precisamente, este boletín revela a Bargalló como un lector profundamente conocedor de la forja disciplinar de la historia de la ciencia que estaba teniendo lugar en otros países a través de la celebración de congresos, la publicación de revistas especializadas y la creación de institutos de investigación. Ello muestra su no menos importante actividad como lector y refuerza el papel de la historia de la ciencia en el conjunto de su obra en España, donde la historia de la ciencia era desatendida por las instituciones académicas de la época, como el mismo Bargalló denunció, sin éxito:

Uno de los fines que nos propusimos al iniciar nuestra publicación fue estimular el interés en el profesorado hacia la historia de las ciencias fisicoquímicas. Nuestro país no se ha interesado como debe por las investigaciones sobre la génesis de la ciencia; debido, tal vez, en parte, a que no ha existido acicate de descubrir ningún oculto tesoro científico nacional, creencia que pudiera pecar de exagerado pesimismo. Urge, como han hecho otras naciones, crear un instituto dedicado a la Historia de las Ciencias, cuyo estudio tanto habrían de contribuir a completar la propia ciencia. ${ }^{109}$

Faraday fue así una apuesta por la pertinencia institucional de la historia de la ciencia que, finalmente, no perduró más allá de 1929. Pese a ello, el proyecto pedagógico bargalliano logró estimular el interés del profesorado hacia la historia de la ciencia a través de sus múltiples obras donde abordaba dicha temática y haciendo de la historia de la ciencia el

\footnotetext{
${ }_{108}$ El propio Bargalló envió a Cajal un ejemplar de su segunda edición del Manual de Química y le invitó a visitar su casa en Guadalajara, donde le esperaban su mujer y su entonces recién nacida hija, Luisa. No obstante, Cajal solía responder a sus cartas declinando las invitaciones debido a la mala salud, de la que se quejaba constantemente: «Carta de Santiago Ramón y Cajal a Modesto Bargalló», 18 de junio de 1927, Epistolario de Santiago Ramón y Cajal, MSS/22109/24, Biblioteca Nacional de España (BNE); «Carta de Modesto Bargalló a Santiago Ramón y Cajal», 21 de noviembre de 1926, Epistolario de Santiago Ramón y Cajal, MSS/22108/174, Biblioteca Nacional de España (BNE); «Carta de Santiago Ramón y Cajal a Modesto Bargalló», 25 de noviembre de 1926, ibíd.
}

109 Modesto Bargalló, «La evolución de las ciencias», Faraday, 7 (1928): 1. 
sustrato sobre el que cimentó su promoción del hábito científico. Más de nueve décadas después, ha sido precisamente el interés de la historia de la ciencia por el profesorado el que ha contribuido a recuperar y ampliar su biografía, nutriéndose de los trabajos pioneros realizados desde la historia de la educación y situándola entre ambas historiografías.

\section{A MODO DE CONCLUSIÓN}

En mayo de 1939 Bargalló cruzó el Atlántico a bordo del Sinaia junto a su hermano Miguel, su esposa Luisa y sus dos hijos Luisa y Miguel. Bargalló se vio forzado a iniciar un nuevo capítulo de su bios y de su ergon en el que tendrán cabida continuidades y rupturas. Futuros trabajos abordarán su labor en México. Asimismo, queda por explorar qué ocurrió con aquel Bargalló que no zarpó en el Sinaia en 1939. Es decir, aquel Bargalló que perduró en los cientos de maestros en formación que pasaron por sus aulas, que leyeron sus múltiples trabajos y que incorporaron y transformaron sus ideas y prácticas. Se trata de cuestiones que pueden ampliar, reforzar y matizar el relato aquí ofrecido, el cual ha mostrado la diversidad de facetas que convergen en un mismo sujeto histórico, lo que a su vez ha posibilitado ampliar, reforzar y matizar diversos aspectos sobre su biografía señalados por los estudios publicados con anterioridad, a los que se aludía al inicio de este trabajo.

Si bien la escritura biográfica constituye un ejercicio de exhaustividad aporética, -esto es, es siempre un ejercicio inacabado- los aspectos subrayados a lo largo de estas páginas han puesto de manifiesto las múltiples potencialidades de las biografías del profesorado de ciencias como punto de encuentro entre historiadores de la educación interesados en la ciencia e historiadores de la ciencia interesados en las aulas. El quehacer de Bargalló superó las lindes de ambas disciplinas, ofreciendo a sus integrantes una plétora de elementos de reflexión crítica sobre cuestiones diversas. Así, a través de su biografía ha sido posible observar el papel activo del público discente y el público lector de la educación científica, mostrando la creatividad del profesorado de ciencias transformando saberes y prácticas científico-pedagógicas a fin de adaptarlas a las características de su alumnado y/o intereses de los lectores, que podían tener diferentes formaciones de origen. La biografía de Bargalló también pone de manifiesto la diversidad de factores que operan tras la 
circulación de las prácticas e ideas pedagógicas, revelando cómo cuestiones curriculares convergen y en ocasiones rivalizan con las propias concepciones del docente sobre la enseñanza o con intereses editoriales. La trayectoria profesional de Bargalló es también un excelente marco para reflexionar sobre las profundas relaciones entre enseñanza e historia de la ciencia, mostrando el papel destacado que esta tuvo en el marco de la renovación pedagógica del primer tercio del siglo XX. En esta línea, la doble mirada discente-docente a la vida y la obra de Bargalló subraya la importancia que tuvieron instituciones como la Escuela de Estudios Superiores del Magisterio y el Museo Pedagógico Nacional en la formación del profesorado en el ideario y las prácticas renovadoras de la época. Asimismo, la biografía de Bargalló ilustra claramente la imbricación de diferentes facetas, identidades profesionales y formaciones disciplinares en los sujetos históricos vinculados a la enseñanza de las ciencias. Así, a través de la trayectoria profesional de Bargalló ha sido posible observar cómo la prensa pedagógica, las traducciones de textos científicos, la industria editorial, las prácticas pedagógicas y la historia de la ciencia son elementos clave y profundamente imbricados en la historia de la enseñanza de las ciencias. Un sujeto permite así transitar al contexto, subrayando el interés metodológico de las biografías para la investigación histórica.

Bargalló confesó en 1932 que "su espíritu» sentía «una debilidad por los hombres de ciencia, nacida de la lectura de sus libros y de sus biografías», como la del célebre científico británico Michael Faraday, que dio nombre a su boletín. ${ }^{110}$ Las biografías de profesores normalistas de ciencias como Bargalló siguen siendo hoy una debilidad tanto en historia de la ciencia como en historia de la educación. El trabajo de recuperación de las biografías de maestros y maestras emprendido por los historiadores de la educación en las últimas décadas, mirando más allá de la alta pedagogía; y de las biografías del profesorado de ciencias de educación secundaria por parte de los historiadores de la ciencia, explorando la ciencia más allá de las disciplinas académicas, constituyen líneas de trabajo que puede inspirar la recuperación de la labor de docentes normalistas de ciencias: biografías que pueden ofrecer respuestas a muchas preguntas por responder y no menos preguntas por

110 Modesto Bargalló, La enseñanza experimental en la escuela y su relación con el desarrollo histórico de la física y de la química (Reus: Ediciones Sardá, 1932), 16. 
formular. La biografía aquí presentada constituye una contribución en este sentido a través de la nada modesta labor educativa y editorial del profesor Modesto Bargalló.

\section{Nota sobre el autor}

Luis Moreno Martínez (Madrid, 1989) es licenciado en Ciencias Químicas por la Universidad Complutense de Madrid, doctor en Didáctica de las Ciencias por la Universidad Autónoma de Madrid y doctor en Historia de la Ciencia por la Universitat de València, donde ha sido Profesor Asociado del Departamento de Historia de la Ciencia y Documentación. Ha recibido diferentes becas y reconocimientos académicos, como el Premio Extraordinario por los estudios de Máster en Historia de la Ciencia y Comunicación Científica, el Premio de la Societat Catalana d'Història de la Ciència i de la Tècnica a jóvenes investigadores, la Beca Juanelo Turriano a Tesis Doctorales en Historia de la Ciencia y la Técnica, que realizó en el Instituto Interuniversitario López Piñero; o una Beca de Excelencia Postdoctoral del Gobierno de México, que desarrolló en el Departamento de Investigaciones Educativas del Cinvestav de Ciudad de México. En paralelo a su quehacer educando en ciencias como Profesor de Educación Secundaria en la Comunidad de Madrid, investiga sobre los usos didácticos de la historia de la ciencia, la historia de la educación científica y la didáctica e historia de la química y la física; además de participar en diversos proyectos de divulgación científica.

\section{REFERENCIAS}

Aduije-Gil, Julia, Alberto Gomis y Manuel Segura. Una mirada a la colección Bargalló. Guadalajara: Universidad de Alcalá de Henares, 2017.

Aragón Albillos, Santiago. «Los premios Ribera: el mecenazgo privado en los tiempos de la institucionalización de la actividad científica en España». En Aulas modernas. Nuevas perspectivas sobre las reformas de la enseñanza secundaria en la época de la JAE, editado por Leoncio López-Ocón, 47-75. Madrid: Dykinson-Universidad Carlos III, 2014.

Audije-Gil, Julia, Fernando Barroso Barcenilla y Manuel Segura Redondo. «The Bargalló Teaching Methodology Research and Geological Heritage». Geoheritage 10, no. 3 (2018): 343-352. 
Audije-Gil, Julia, Fernando Barroso Barcenilla y Manuel Segura Redondo. «Recuperación de la Colección Histórica Bargalló de la Universidad de Alcalá». Geo-Temas 16, n. 2 (2016): 235-238.

Baratas, Alfredo, Antonio Bueno y Pedro Ruíz Castell. 150 años de la Facultad de Ciencias. Madrid: Universidad Complutense de Madrid, 2007.

Bernal Martínez, José Mariano. Renovación pedagógica y enseñanza de las ciencias. Medio siglo de propuestas pedagógicas y experiencias escolares (18821936). Madrid: Biblioteca Nueva, 2001.

Bertomeu Sánchez, José Ramón. «Beyond Borders in the History of Science Education». En Relocating the History of Science: Essays in Honor of Kostas Gavroglu, editado por Theodore Arabatzis, Jürgen Renn y Anna Simoes, 159-173. Dordrecht: Springer, 2016.

Burdiel, Isabel y Roy Foster. La historia biográfica de Europa. Nuevas perspectivas. Zaragoza: Fundación Fernando El Católico, 2015.

Carral, Diego. «Modesto Bargalló: El arte de educar en la naturaleza». Actas del XVIII Coloquio de Historia de la Educación, n. ${ }^{\circ} 2$ (2015): 481-486.

Checa Godoy, Antonio. Historia de la prensa pedagógica en España. Sevilla: Publicaciones de la Universidad de Sevilla, 2002.

Cueli, José. «Matemáticas, físicas y química». En El exilio español en México, 1939-1982, editado por Salvador Reyes Nevares, 531-543. México: Fondo de Cultura Económica, 1982.

Dosse, François. La apuesta biográfica. Escribir una vida. Valencia: Publicaciones de la Universitat de València, 2007.

Ferrer Culubret y Salvador Maura. Una institución docente española: La Escuela de Estudios Superiores del Magisterio, 1909-1932. Madrid: Cedesa, 1973.

García Bernal, Silvia Mónica. Los maestros del exilio español en el Instituto Politécnico Nacional. Ciudad de México: Ediciones IPN, 2014.

Garritz, Andoni y Ricardo Valdez. «Modesto Bargalló Ardévol. Un químico español que se transformó en mexicano». Educación Química 19, n. ${ }^{\circ} 1$ (2008): 1-8.

Garriz, Andoni, Santiago Capella, José Antonio Chamizo y Julián Garritz. «Exiled Chemists of the Spanish Civil War's Footprint in Mexico». History Research 3, n. ${ }^{\circ} 1$ (2013): 16-25.

Giral, Francisco. Ciencia española en el exilio (1939-1989). El exilio de los científicos españoles. Barcelona: Antrophos, 1994.

González Pérez, Teresa. «Aprender a enseñar en el siglo XIX: La formación inicial de las maestras». Revista Electrónica Interuniversitaria de Formación del Profesorado 14, n. ${ }^{\circ} 4$ (2010): 133-143.

Guijarro Mora, Víctor. Artefactos y acción educativa. La cultura del objeto científico en la enseñanza secundaria en España (1845-1930). Madrid: Dykinson, 2018. 
Ihde, Aaron J. «The history of the Dexter Award. Part IV: The Third Decade». Bulletin for the History of Chemistry, n. ${ }^{\circ}$ 4(1989): 23-26.

Mainer Baqué, Juan. La forja de un campo profesional. Pedagogía y didáctica de las ciencias sociales en España (1900-1970) (Madrid: CSIC, 2009).

Martín Sánchez, Manuela, Gabriel Pinto Cañón y María Teresa Martín Sánchez. «Una aproximación a la historia de la enseñanza de la química universitaria en España». Anales de Química 113, 2(2017): 100-112.

Molero, Antonio y María del Mar del Pozo Andrés. Un precedente histórico en la formación universitaria del profesorado español. La Escuela de Estudios Superiores del Magisterio (1909-1936). Madrid: Universidad de Alcalá de Henares, 1989.

Moreno Martínez, Luis. «Ciencia en las aulas: Prácticas pedagógicas, cultura material e historia de la ciencia en la obra de Modesto Bargalló en España (1894-1939)». PhD diss., Universitat de València, 2020.

Nieto-Galan, Agustí. The Politics of Chemistry. Science and Power in Twentieth-Century Spain. Cambridge: Cambridge University Press, 2019.

Noguera Arrom, Juana. La Escuela Normal de Tarragona, 1843-1931. Cien años de vida de una escuela normal. Barcelona: Publicaciones de la Universidad de Barcelona, 1984.

Nye, Mary Jo. «Scientific biography: History of Science by Another Means?». Isis 97, 2 (2006): 322-329.

Pozo Andrés, María del Mar del. Justa Freire o la pasión de educar: Biografía de una maestra atrapada en la historia de España (1896-1965). Barcelona: Octaedro, 2013.

Pozo Andrés, María del Mar del. «El movimiento de la escuela nueva y la renovación de los sistemas educativos». En Historia de la Educación (Edad Contemporánea), editado por Alejandro Tiana, Gabriela Ossebach y Florentino Sanz, 189-215. Madrid: UNED, 2009.

Pozo Andrés, María del Mar, Alejandro Díez Torre y Manuel Segura Redondo. «El modelo de enseñanza metodológica de las ciencias en Modesto Bargalló en el ámbito del plan profesional del Magisterio (1931-1936)». Enseñanza de las Ciencias 3, n. ${ }^{\circ}$ extra. 1 (1985): 24.

Pozo Andrés, María del Mar del, Manuel Segura Redondo y Alejandro Díez Torre. Guadalajara en la historia del magisterio español (1839-1939), cien años de formación del profesorado. Guadalajara: Publicaciones de la Universidad de Alcalá de Henares, 1986.

Recasens, José María y José Sánchez Real. El Instituto de Enseñanza Media "Antonio Martí y Franqués» de Tarragona (1845-1965). Contribución al conocimiento de la historia de sus primeros 120 años. Tarragona: Ayuntamiento de Tarragona, 1969.

Reyes Nevares, Salvador. El exilio español en México, 1939-1982. México: Fondo de Cultura Económica, 1982. 
Ribagorda, Álvaro. El coro de Babel. Las actividades culturales de la Residencia de Estudiantes. Madrid: Publicaciones de la Residencia de Estudiantes, 2011.

Sáenz de la Calzada, Margarita. La Residencia de Estudiantes. Los Residentes. Madrid: CISC-Residencia de Estudiantes, 2011.

Segura Redondo, Manuel, Alejandro Díez Torre y María del Mar del Pozo Andrés. «Aportaciones a la didáctica de las ciencias naturales de Modesto Bargalló durante su etapa de docencia en la Escuela Normal de Guadalajara (1914-1936)». En Actas del III Congreso de la Sociedad Española de Historia de las Ciencias, 215-242. San Sebastián: Sociedad Española de Historia de las Ciencias y de las Técnicas, 1984.

Segura, Manuel, Alberto Gomis y José María Sánchez Jiménez. «Modesto Bargalló Ardévol (1894-1981), maestro de maestros e historiador de la ciencia». Llull, n. 34 (2011), 74: 419-442.

Segura, Manuel y Alberto Gomis. «Las comunicaciones paleontológicas de Modesto Bargalló presentadas en la Real Sociedad Española de Historia Natural». Boletín de la Real Sociedad Española de Historia Natural, n. 106 (2012): 85-98.

Söderqvist, Thomas "No Genre of History Fell Under More Odium than that of Biography": The Delicate Relations Between Scientific Biography and the Historiography of Science». En The History and Poetics of Scientific Biography, editado por Thomas Söderqvist, 242-262. Nueva York: Routledge, 2007. Söderqvist, Thomas. The Historiography of Contemporary Science, Technology and Medicine. Writing recent science. Nueva York: Routledge, 2006.

Truyols, Jaime y Manuel Segura. «Contribuciones de Modesto Bargalló al conocimiento de la geología de la Alcarria». Geogaceta, n. ${ }^{\circ} 20$ (1996): 1429-1432. 